OPEN ACCESS

Edited by:

Javier Echeverria,

University of Santiago, Chile

Reviewed by:

Jen-Tsung Chen,

National University of Kaohsiung,

Taiwan

Kuldeep Dhama,

Indian Veterinary Research Institute

(IVRI), India

*Correspondence:

Shreesh Ojha

shreeshojha@uaeu.ac.ae

tThese authors have contributed equally to this work

Specialty section: This article was submitted to

Ethnopharmacology,

a section of the journal

Frontiers in Pharmacology

Received: 31 July 2020 Accepted: 04 February 2021

Published: 14 May 2021

Citation:

Jha NK, Sharma C, Hashiesh HM,

Arunachalam S, Meeran MFN, Javed H, Patil CR, Goyal SN and Ojha S (2021) $\beta$-Caryophyllene, A

Natural Dietary CB2 Receptor

Selective Cannabinoid can be a Candidate to Target the Trinity of Infection, Immunity, and

Inflammation in COVID-19.

Front. Pharmacol. 12:590201. doi: 10.3389/fphar.2021.590201

\section{$\beta$-Caryophyllene, A Natural Dietary CB2 Receptor Selective Cannabinoid can be a Candidate to Target the Trinity of Infection, Immunity, and Inflammation in COVID-19}

\author{
Niraj Kumar Jha ${ }^{1 \dagger}$, Charu Sharma ${ }^{2 \dagger}$, Hebaallah Mamdouh Hashiesh ${ }^{3}$, \\ Seenipandi Arunachalam ${ }^{3}$, MF Nagoor Meeran ${ }^{3}$, Hayate Javed ${ }^{4}$, Chandragouda R. Patil ${ }^{5}$, \\ Sameer N. Goyal ${ }^{6}$ and Shreesh Ojha ${ }^{3 *}$ \\ ${ }^{1}$ Department of Biotechnology, School of Engineering \& Technology (SET), Sharda University, Greater Noida, India, ${ }^{2}$ Department \\ of Internal Medicine, College of Medicine and Health Sciences, United Arab Emirates University, Al Ain, United Arab Emirates, \\ ${ }^{3}$ Department of Pharmacology and Therapeutics, College of Medicine and Health Sciences, United Arab Emirates University, Al \\ Ain, United Arab Emirates, ${ }^{4}$ Department of Anatomy, College of Medicine and Health Sciences, United Arab Emirates University, \\ Al Ain, United Arab Emirates, ${ }^{5}$ Department of Pharmacology, Delhi Pharmaceutical Sciences and Research University, New Delhi, \\ India, ${ }^{6}$ Shri Vile Parle Kelvani Mandal's Institute of Pharmacy, Dhule, India
}

Coronavirus disease (COVID-19), caused by novel severe acute respiratory syndrome coronavirus 2 (SARS-CoV-2), is an ongoing pandemic and presents a public health emergency. It has affected millions of people and continues to affect more, despite tremendous social preventive measures. Identifying candidate drugs for the prevention and treatment of COVID-19 is crucial. The pathogenesis and the complications with advanced infection mainly involve an immune-inflammatory cascade. Therefore, therapeutic strategy relies on suppressing infectivity and inflammation, along with immune modulation. One of the most promising therapeutic targets for the modulation of immune-inflammatory responses is the endocannabinoid system, particularly the activation of cannabinoid type 2 receptors (CB2R), a G-protein coupled receptor which mediates the anti-inflammatory properties by modulating numerous signaling pathways. To pharmacologically activate the CB2 receptors, a naturally occurring cannabinoid ligand, beta-caryophyllene (BCP), received attention due to its potent anti-inflammatory, antiviral, and immunomodulatory properties. BCP is recognized as a full selective functional agonist on $\mathrm{CB} 2$ receptors and produces therapeutic effects by activating CB2 and the nuclear receptors, peroxisome proliferator-activated receptors (PPARs). BCP is regarded as the first dietary cannabinoid with abundant presence across cannabis and non-cannabis plants, including spices and other edible plants. BCP showed tissue protective properties and favorably modulates numerous signaling pathways and inhibits inflammatory mediators, including cytokines, chemokines, adhesion molecules, prostanoids, and eicosanoids. Based on its pharmacological properties, molecular mechanisms, and the therapeutic potential of BCP as an immunomodulator, anti-inflammatory, organprotective, and antiviral, we hypothesize that BCP could be a promising therapeutic and/or preventive candidate to target the triad of infection, immunity, and inflammation in 
COVID-19. In line with numerous studies that proposed the potential of cannabinoids in COVID-19, BCP may be a novel candidate compound for pharmaceutical and nutraceutical development due to its unique functional receptor selectivity, wide availability and accessibility, dietary bioavailability, nonpsychoactivity, and negligible toxicity along with druggable properties, including favorable pharmacokinetic and physicochemical properties. Based on reasonable pharmacological mechanisms and therapeutic properties, we speculate that BCP has potential to be investigated against COVID-19 and will inspire further preclinical and clinical studies.

Keywords: COVID-19, SARS-CoV-2, beta-caryophyllene, immunomodulators, natural products

\section{INTRODUCTION}

COVID-19, a public health emergency and pandemic, has affected millions of people worldwide and continues to do so, despite numerous preventive measures, and this situation will continue until a vaccine is developed (Huang et al., 2020). The severity of infection varies from patients being asymptomatic to pre-symptomatic to symptomatic with different stages of illness, ranging from mild, moderate, to severe (Yang et al., 2020). The symptoms include fever, dry cough, sore throat, diarrhea, rashes on the skin, face, or toes, shortness of breath, loss of smell, anorexia, fatigue, headache, myalgia, anosmia, and ageusia, identified as the clinical criteria for diagnosis of COVID-19 (Jin et al., 2020). The majority of deaths are happening due to complications, such as severe pneumonia, acute respiratory distress syndrome (ARDS), shock, sepsis, and resultant multiorgan failure (Huang et al., 2020; Yang et al., 2020). The pathogenesis of COVID-19 emerges as a multifaceted, multisystem, multi-organ disorder, including viremia to overt the activation of immune responses and inflammatory processes that result in a dysregulated immune pattern, manifested by a massive rise in the levels of pro-inflammatory cytokines, chemokines, and adhesion molecules (Dhama et al., 2020). This causes the onset of a "cytokine storm" or "cytokine release syndrome", which mainly causes ARDS and further leads to pathogenic effects through a quite ubiquitous target at a multiple-organ level (Dhama et al., 2020; Tang et al., 2020; Vinciguerra et al., 2020).

At present, many drugs are being repurposed for supportive management in COVID-19 based on docking studies, pharmacological rationale, and clinical experiences (Jean and Hsueh, 2020; Kandeel and Al-Nazawi, 2020; Rabaan et al., 2020; Singh et al., 2020). The pathogenesis and the complications developed with the infection mainly involve an immune-inflammatory cascade; therefore, the therapeutic strategies focus on reducing inflammation and immune modulation of this cascade (Dhama et al., 2020; García, 2020; Scavone et al., 2020; Zhou et al., 2020). Despite recent availability of vaccine for prophylaxis, massive efforts are ongoing for the discovery of novel drugs for the treatment and prevention of COVID-19 (Jean and Hsueh, 2020; Kandeel and Al-Nazawi, 2020; Rabaan et al., 2020; Singh et al., 2020). In parallel with repurposing modern medicines, there are numerous attempts to explore natural products with potential to target the interplay of viral infection and immune-inflammatory axis (Bahramsoltani and Rahimi, 2020; Basu et al., 2020; Benarba and Pandiella, 2020; Hensel et al., 2020; Mondal et al., 2020; Narkhede et al., 2020). Over the past few months it has been suggested that natural products hold great promise in the management of COVID-19 due to their antiviral, anti-inflammatory, and immunomodulator activities (Bahramsoltani and Rahimi, 2020; Basu et al., 2020; Benarba and Pandiella, 2020; Mondal et al., 2020; Narkhede et al., 2020). Thus, identifying candidate compounds which have selectivity against viral components as well as prevent viral entry, enhance immunity and attenuate inflammatory factors in host could be important in context to COVID-19.

Many propositions have been made on the possible therapeutic potential of essential oils-derived phytochemicals, including many terpenes or terpeno-alcoholic compounds, in COVID-19 (Asif et al., 2020; Boukhatem and Setzer, 2020; da Silva et al., 2020; Diniz et al., 2021). Many of the terpene components present in cannabis are widely consumed in food and used in traditional medicine (Anil et al., 2021). Some of these compounds showed potential to modulate the endocannabinoid system, which represents one of the newest therapeutic targets in regard to regulation of innate and adaptive immunity and immunomodulatory and anti-inflammatory properties. The endocannabinoid system is targeted by plant-derived compounds, termed phytocannabinoids, which have gained attention for therapeutic modulation of cannabinoid type-1 receptors (CB1R) and type-2 (CB2R), the components of endocannabinoid system (Oláh et al., 2017). The latest therapeutic strategy in targeting the endocannabinoid system is to activate the CB2R, a G-protein coupled receptor which appears to regulate immunity, inflammation, and pain. The activation of CB2R has been shown to exert potent antiinflammatory, immunomodulatory, and organ-protective properties with no psychotropic effects, which are commonly observed with CB1R. Over the past few months, it has been suggested that modulation of the endocannabinoid system by cannabinoids, including cannabidiol, could be useful in prophylaxis and treatment of COVID-19 and may improve prognosis (Costiniuk and Jenabian, 2020; Esposito et al., 2020). Recently, extract of Cannabis sativa containing phytocannabinoids and terpenes were shown to modulate the inflammatory mediators in alveolar epithelial cells (A549) in COVID-19-associated inflammation and suggested that the phytocannabinoid mix formulation exerted better activity in 


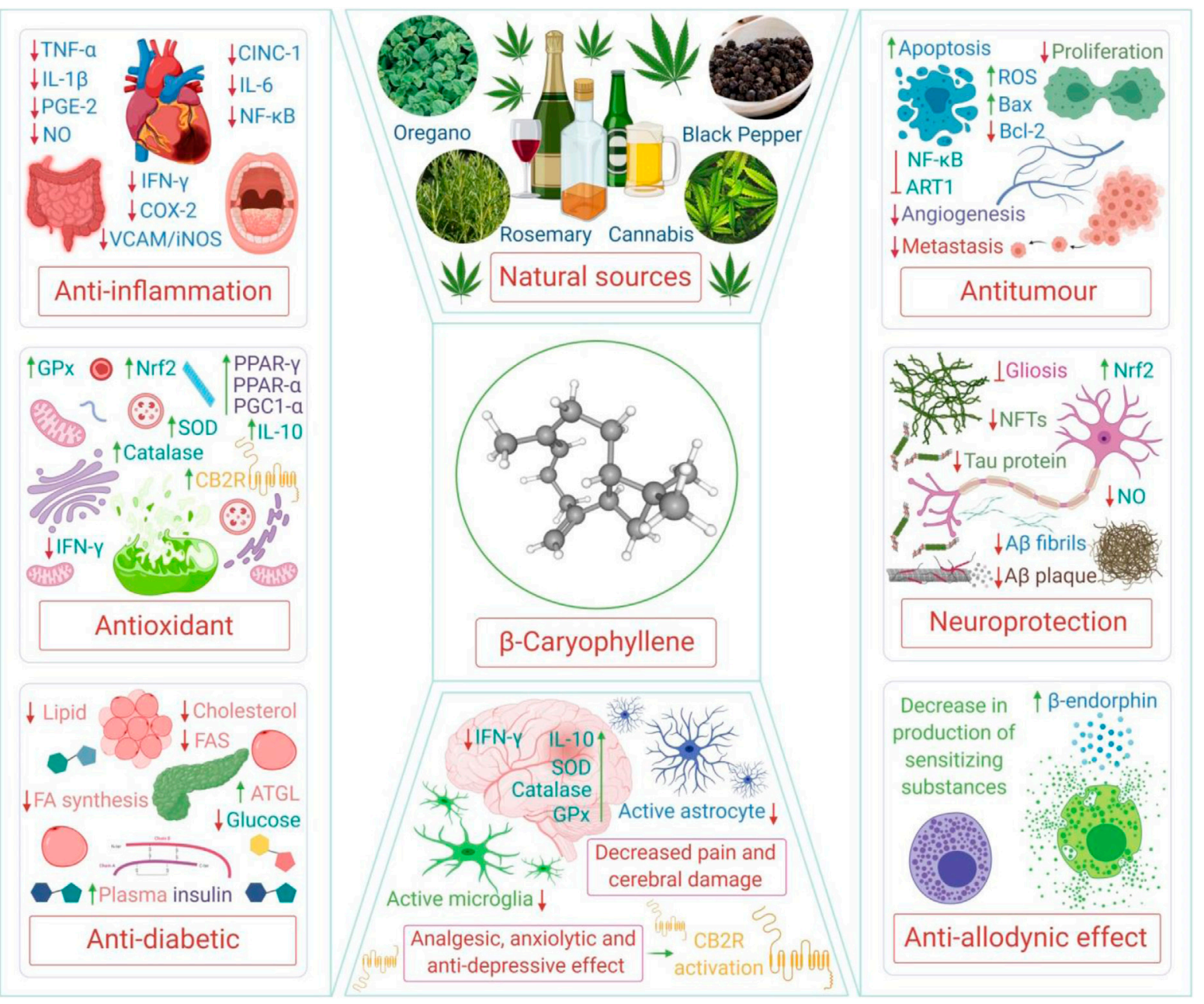

FIGURE 1 | The structure and various polypharmacological properties and therapeutic potential of BCP. TNF-a, tumor necrosis factor alpha; IL, interleukin; PGE-2, prostaglandin E2; NO, nitric oxide; CINC-1, cytokine-induced neutrophil chemoattractant 1; NF-kB, nuclear factor kappa B; IFN- $\gamma$, interferon gamma; COX-2, cyclooxygenase-2; VCAM, vascular cell adhesion protein; iNOS, inducible nitric oxide synthase; GPx, glutathione peroxidase; SOD, superoxide dismutase; PPAR- $\gamma$, peroxisome proliferator-activated receptor gamma; PGC1- $\alpha$, peroxisome proliferator-activated receptor gamma coactivator 1-alpha; Nrf2, nuclear factor erythroid 2-related factor 2; FAS, fatty acid synthase; ATGL, adipose triglyceride lipase; ROS, reactive oxygen species; Bax, Bcl-2 associated X protein; Bcl-2, B-cell lymphoma 2; ART1, arginine ADP-ribosyltransferase 1; NFTs, neurofibrillary tangles; A $\beta$, amyloid beta; CB2R, cannabinoid receptor type 2.

comparison with individual fractions from cannabis (Anil et al., 2021). Many cannabinoids, including cannabidiol, have been suggested for their possible potential as preventive agents or therapeutic adjuvants with other agents in targeting the trinity of infection, inflammation, and immunity in COVID-19 (Byrareddy and Mohan, 2020; Costiniuk and Jenabian, 2020; Esposito et al., 2020; Nagarkatti et al., 2020; Sexton, 2020; Raj et al., 2021).

Among numerous cannabinoids, beta-caryophyllene ( $\beta$-Caryophyllene; $\mathrm{BCP})$, a naturally occurring terpene, has received enormous attention in the past few years due to its recognition as a full functional agonist on CB2R which imparts its therapeutic potential by mediating anti-inflammatory and immunomodulatory properties (Gertsch et al., 2008). BCP, chemically known as trans-(1R,9S)-8-Methylene-4,11,1 is the first dietary cannabinoid of natural origin, with an abundant presence in a variety of spice blends and citrus flavors, as an additive or preservative, and for aroma in food products and beverages (Gertsch, 2008; Gertsch et al., 2008). BCP is one of the constituents of commonly consumed edible plants, such as cinnamon (Cinnamomum spp.), basil (Ocimum spp.), pepper (Piper spp.), breakfast mint [Perilla frutescens (L.) Britton], coriander (Coriandrum sativum L.), chestnut (Aesculus hippocastanum L.), sage (Salvia officinalis L.), cubeb pepper (Piper cubeba L.f.), thyme (Thymus vulgaris L.), myrrh [Myrrhis odorata (L.) Scop.], curry leaves [Murraya koenigii (L.) Spreng.], hops (Humulus lupulus L.), cloves [Syzygium aromaticum (L.) Merr. \& L.M. Perry], hemp (Cannabis sativa L.), lavender (Lavandula angustifolia Mill.), oregano (Origanum vulgare L.), and rosemary (Rosmarinus officinalis L.), among others. Recently, a majority of the plant derived compounds showed potential in COVID-19 due to their antioxidant and antiinflammatory properties and are of limited occurrence in certain 
genera and species or to a specific individual plant that may limit supply and demand. However, BCP is unique in terms of wide dietary availability and accessibility across numerous plant genera and species (Sharma et al., 2016). Till date, the presence of BCP has been confirmed in more than two thousand plants, including edible, medicinal, and ornamental plants. BCP is mainly synthesized by plants as a defense mechanism against insects and aphids, and plays a role in pollination. It is usually localized in the aerial parts of the plants including leaves, flowers, spate, inflorescence, and buds, with a low presence in the stem, roots, and rhizomes (Sharma et al., 2016). The structure and various polypharmacological properties and therapeutic potential of BCP are depicted in Figure $\mathbf{1}$.

In a recent molecular docking study, 171 components, including BCP, present in the essential oils of numerous plants were analyzed against SARS-CoV-2 main protease (SARS-CoV$2 \mathrm{M}^{\mathrm{pro}}$ ), SARS-CoV-2 endoribonucleoase (SARS-CoV-2 Nsp15/ NendoU), SARS-CoV-2 ADP-ribose-1" -phosphatase (SARSCoV-2 ADRP), SARS-CoV-2 RNA-dependent RNA polymerase (SARS-CoV-2 RdRp), the binding domain of the SARS-CoV-2 spike protein (SARS-CoV-2 rS), and human angiotensin-converting enzyme (hACE2) (da Silva et al., 2020). Very recently in an in silico study, BCP was shown to target $\mathrm{M}^{\text {pro }}\left(3 \mathrm{CL}^{\text {pro }}\right)$, the main protease in SARS-CoV-2 involved in the processing of translating the viral RNA into the viral polyproteins (Narkhede et al., 2020). BCP interacted with the amino acid residues of SARS-CoV-2 via pie-alkyl interactions and showed good affinity along with druggable properties (Narkhede et al., 2020). In another recent study, Muthuramalingam et al., 2020 (Muthuramalingam et al., 2020) carried out a cheminformatics and interactome study using in silico approaches and found that BCP is one of the potential compounds among 259 phytochemicals screened for targeting thirteen COVID-19 immune genes regulating numerous signaling pathways. The study unveiled that 154 compounds interact with COVID-19-associated immune genes. BCP and its derivative, $\beta$-caryophyllene oxide, was found to target immune genes, and was suggested useful for designing and developing as a potential agent against COVID-19 (Muthuramalingam et al., 2020).

The present review scientifically contemplates the therapeutic prospects of BCP in COVID-19. The possibilities of BCP as a candidate in COVID-19 have been discussed based on reported findings, particularly immunomodulatory, anti-inflammatory, and antiviral properties. Additionally, CB2R activation has been suggested as a possible therapeutic target in COVID-19. Based on the role of $\mathrm{CB} 2 \mathrm{R}$ in immune-inflammatory mechanisms, we hypothesized that $\mathrm{BCP}$ endowed with $\mathrm{CB} 2 \mathrm{R}$ agonist properties may potentially limit the severity and progression of COVID-19 by modulating infection, immunity, and inflammation. The potent anti-inflammatory activity mediating multiple pathways and mediators of inflammation, including the inhibition of pro-inflammatory cytokines, chemokines, and adhesion molecules, along with the suppression of macrophage infiltration and neutrophilendothelial cell interaction, might constitute a promising pharmacological and nutritional approach to inhibit the cytokine storm, which is a major reason for death in COVID19. The potential of BCP in improving host cellular immunity against infection and its good antiviral and antibacterial activity, along with the antioxidant effects, may further help in controlling the symptoms and the worsening of the disease, secondary infections, complications, progression, and resultant death. $\mathrm{BCP}$ has potential to protect from the risk factors, prevent the entry of the virus, and ameliorate organ damage and the pathological manifestation of SARS-CoV-2 on the different organ systems. A scheme of the effect of BCP mediating CB2R activation has been proposed in context of infection, inflammation, and immunity in COVID-19 (Figure 2).

The literature reviewed herein indicates that $\mathrm{BCP}$ may be a promising candidate as a preventive and therapeutic agent or adjuvant for COVID-19 given its pharmacological and molecular mechanisms, including its CB2R agonist property, integrating with its antiviral, anti-inflammatory, and immunomodulatory properties in numerous experimental studies (Sharma et al., 2016). However, no study has yet directly demonstrated the efficacy of BCP against SARS-CoV-2 infections. But, based on pharmacological properties, a logical approach has been presented on the therapeutic potential of BCP in COVID-19.

\section{BCP AS A FUNCTIONAL CB2 RECEPTOR AGONIST}

Gertsch and colleagues first recognized $\mathrm{BCP}$ as a functional CB2R agonist using numerous model systems, including in silico, in vitro, and in vivo studies (Gertsch et al., 2008). In the molecular docking studies, BCP was observed to interact with CB2R on the same binding sites as that of CP55, 940, a CB2R agonist. It binds well in a hydrophobic sac involving lipophilic amino acid residues and it was suggested that the double bond with conformation E of BCP is vital for the receptor binding (Gertsch et al., 2008). Accumulating experimental studies have demonstrated the CB2R activation mediated effects of BCP in attenuating inflammation, oxidative stress, apoptosis, fibrosis, and immune modulation. The CB2R-dependent antiinflammatory mechanism of BCP has been demonstrated in oral mucositis (Picciolo et al., 2020), glioblastoma (Irrera et al., 2020), neuropathic pain (Klauke et al., 2014; Aly et al., 2019), bipolar disorders (Hwang et al., 2020), wound healing (Koyama et al., 2019), interstitial cystitis (Berger et al., 2019), autoimmune encephalomyelitis/multiple sclerosis (Alberti et al., 2017; Askari et al., 2019), neurocognitive disorders (Lindsey et al., 2019; Chávez-Hurtado et al., 2020), arthritis (Irrera et al., 2019), metabolic and neurobehavioral alterations (Youssef et al., 2019), insulin resistance and vascular inflammation (Youssef et al., 2019), hyperglycemia (Basha and Sankaranarayanan, 2016), peripheral neuropathy (Segat et al., 2017), atherosclerosis (Zhang et al., 2017), cardiotoxicity (Meeran et al., 2019), osteoporosis (Shan et al., 2017), vascular dementia (Lou et al., 2017), dopaminergic neurodegeneration/ Parkinson's disease (Javed et al., 2016), Alzheimer's disease (Cheng et al., 2014), cerebral ischemia-reperfusion (Poddighe et al., 2018), liver fibrosis (Mahmoud et al., 2014), pulmonary 


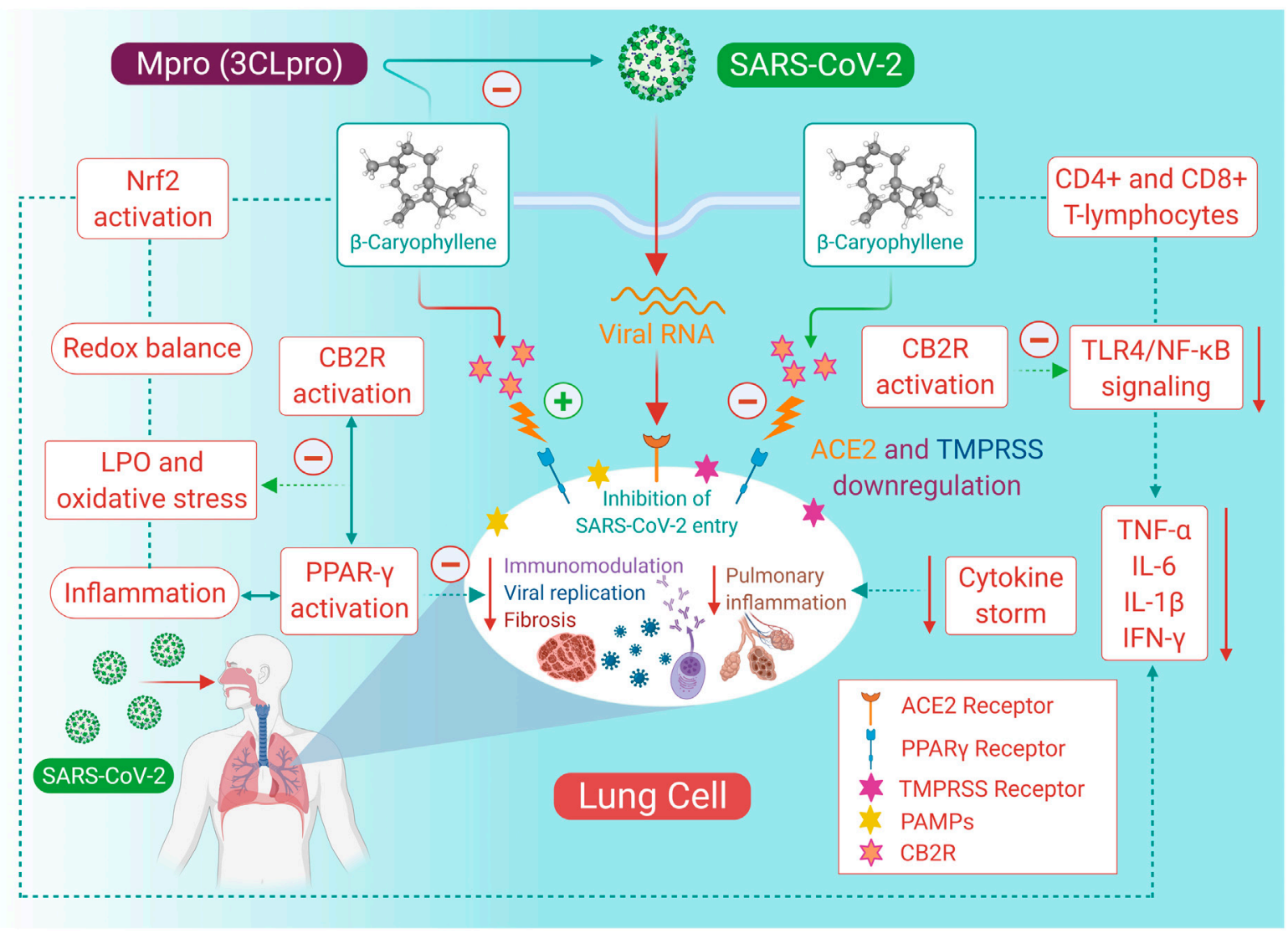

FIGURE 2 | The proposed possible mechanisms and potential of BCP in COVID-19.

inflammation (Andrade-Silva et al., 2016), intestinal inflammation (Bento et al., 2011), acute myocardial infarction (Younis and Mohamed, 2019), acute renal injury (Horváth et al., 2012), diabetic nephropathy (Li et al., 2020), and lipid disorders (Youssef et al., 2019).

In the majority of the experimental models involving inflammatory states similar to those of human diseases, the principal pharmacological and molecular mechanism observed is the inhibition of pro-inflammatory cytokines, NF- $\kappa \mathrm{B}$, adhesion molecules, and chemokines and the subsequent modulation of signaling pathways, mainly involving toll-like receptors, opioid receptors, SIRT1/PGC-1a, AMPK/CREB, MAPK/ERK, Nrf2/ Keap1/HO-1, and the activation of nuclear peroxisome proliferator-activated receptors (PPARs). Cannabinoids are known to interact or crosstalk with a family of PPARs, including three subtypes: PPAR- $\alpha$, PPAR- $\beta / \delta$, and PPAR- $\gamma$. These subtypes are encoded by distinct genes and are regulated by steroids and lipid metabolites and mainly control lipid and glucose homeostasis and inflammatory responses (O'Sullivan, 2016). PPAR- $\gamma$ agonists, pharmacologically known as thiazolidinediones, are clinically available drugs for use as insulin sensitizers in insulin resistance/type 2 diabetes mellitus. Recently, thiazolidinedione has been suggested for repurposing in COVID-19 due to its potential to attenuate cytokine storms
(Ciavarella et al., 2020). PPAR- $\gamma$ agonists were shown to inhibit the replication of numerous viruses, including human immunodeficiency virus, respiratory syncytial virus, hepatitis B, and hepatitis C viruses (Skolnik et al., 2002; Du et al., 2017). Further, PPAR- $\gamma$ agonists have been shown to reduce morbidity and mortality in influenza A virus infections (Bassaganya-Riera et al., 2010). The activation of PPAR- $\gamma$ in resident alveolar macrophages was reported to significantly ameliorate pulmonary inflammation and enhance host recovery following respiratory viral infections (Huang et al., 2019). Following amelioration of the tissue damage, PPAR- $\gamma$ activation also controls the overproduction of cytokines. Thus, BCP may pause the onset of the cytokine storm from resident macrophages.

In addition to activation of CB2R, BCP also activates PPAR- $\alpha$ which favorably modulates the lipid metabolism by increasing the ability of hormone nuclear receptors PPAR- $\alpha$ and estrogenrelated receptor $\alpha(E R R \alpha)$ to drive the transcription of fatty acid oxidation enzymes by increasing the levels of peroxisome proliferator-activated receptor-gamma coactivator $1 \alpha$ (PGC-1 $\alpha$ ), as well as stimulating sirtuin 1 (SIRT1) deacetylase activity (Zheng et al., 2013; Wu et al., 2014). The role of sirtuin in the transcription and replication of viruses is well known and the activation of PPAR- $\alpha$ and lipolysis showed to reduce hepatitis $\mathrm{C}$ virus genotype-associated lipid metabolic disorder in liver 
diseases (Patra et al., 2019). PPAR- $\alpha$ activation was also shown to beneficially influence inflammation in alveolar epithelial cells, suggesting a potentially beneficial role of PPAR- $\alpha$ in ARDS (Hecker et al., 2015). Thiazolidinediones have shown numerous adverse effects, such as weight gain, osteoporosis, heart failure, stroke, and an increased risk of urinary cancer. Since BCP is natural, non-toxic, and devoid of the adverse effects of synthetic cannabinoids, it could be a safer alternative over synthetics. Together, the role of BCP as a PPAR- $\gamma$, as well as a PPAR- $\alpha$ agonist, seems promising in the regulation of the lipid and glucose metabolism, along with additional regulatory roles on cell proliferation and differentiation, vascular homeostasis, and inflammation, and the immune systems. Thus, BCP may be possibly useful to control the orchestrated immuneinflammatory events in COVID-19.

\section{IMMUNOMODULATORY PROPERTIES OF BCP}

SARS-CoV-2 enters the host cells by binding to ACE2 receptors and the pathogen associated molecular patterns (PAMPs) on the virus alert innate immune cells, the anti-viral effectors, such as $\mathrm{T}$ CD8+ cells, NK cells, neutrophils, monocytes, and macrophages about the presence of the invading virus. The innate immune cells, which express pattern recognition receptors (PRRs), such as toll-like receptors (TLRs), retinoic acid-inducible gene I (RIG-I)like receptors (RLRs), and nucleotide-binding and oligomerization domain (NOD)-like receptors (NLRs), detect PAMPs to achieve a suitable immune response against the invading pathogen (Keam et al., 2020). PRR and PAMP interaction triggers phagocytosis and stimulates the synthesis of pro-inflammatory cytokines, such as type I interferon, IFN $\alpha / \beta$ and type II, IFN- $\gamma$, and chemokines, such as CXCL-10 and CCL-2, to onset an antiviral environment (Allegra et al., 2020).

In the case of severe infection, the viruses are sensed by monocytes, tissue macrophages, and resident dendritic cells, resulting in an uncontrolled pro-inflammatory cytokines (IFN, TNF- $\alpha$, IL- $1 \beta$, and IL-6) production, leading to a phenomenon called a "cytokine storm", which damages the respiratory epithelial cells of the host (Allegra et al., 2020). The immune responses are critical for the eradication of the virus and the resolution of the active disease. $\mathrm{CB} 2 \mathrm{R}$ represents an important receptor target for immune regulation and is predominantly expressed by immune cells of the immune system, such as B cells, T cells, CD8+ lymphocytes, CD4+ lymphocytes, NK cells, neutrophils, macrophages, basophils, eosinophils, platelets, mast cells, dendritic cells, microglia, and astrocytes (Howlett and Abood, 2017). The CB2R are well expressed in several organs, including the liver, spleen, thymus, brain, lungs, kidneys, tonsils, nasal epithelium, and PBMC, which are present in the pancreas, uterus, and reproductive tissues (Cabral et al., 2015). Both cannabinoid receptors, CB1R and CB2R, play an important role in the modulation of the immune system, potentially inducing immunosuppression (Cabral et al., 2015; Hernández-Cervantes et al., 2017). The therapeutic targeting of
CB2R has received enormous attention, since these novel therapeutic agents would have no psychotropic effects, as is the case with CB1R.

Human CB2R were first cloned in 1993 from the promyelocytic leukemia cell line HL-60 (Munro et al., 1993) and the first CB2R-deficient mouse was generated in 2000 (Buckley et al., 2000); therefore, CB2R represent the relatively newest therapeutic targets. Mice deficient in CB2R showed an increased susceptibility and vulnerability to influenza infection, demonstrating that $\mathrm{CB} 2 \mathrm{R}$ are important in immunoregulation in respiratory viral infections (Kapellos et al., 2019). The activation of CB2R exerted potent immunomodulation, mediating cell death induction, cytokine suppression, and inhibition of cell proliferation, along with the stimulation of regulatory $\mathrm{T}$ cell induction and anti-inflammatory cytokines (Rieder et al., 2010; Karmaus et al., 2012). However, few studies notably demonstrate that $\mathrm{CB} 2 \mathrm{R}$ may modulate susceptibility to the experimental cerebral malaria through a CCL17-dependent mechanism (Alferink et al., 2016).

Since the recognition of $\mathrm{BCP}$ as an agonist of $\mathrm{CB} 2 \mathrm{R}$, numerous studies have demonstrated the therapeutic benefits of $\mathrm{BCP}$ by suppressing immune-inflammatory cascade when $\mathrm{CB} 2 \mathrm{R}$ are activated. The activation of $\mathrm{CB} 2 \mathrm{R}$ was reported to suppress lung pathology in infants infected with acute respiratory syncytial virus by reducing the levels of cytokines and chemokines (Tahamtan et al., 2018). In HIV patients, the activation of $\mathrm{CB} 2 \mathrm{R}$ was shown to impair a productive infection and viral transmission involving a crosstalk/ interaction between CB2R (Costantino et al., 2012) and to inhibit the replication of the virus in monocytes and macrophages (Ramirez et al., 2013). Recently, BCP was shown to modulate systemic and local immunity in an experimental autoimmune encephalomyelitis model (Askari et al., 2019) and the immunomodulatory effect has been attributed to the ability of $\mathrm{BCP}$ to inhibit $\mathrm{CD} 4+$ and $\mathrm{CD} 8+\mathrm{T}$ lymphocytes and proinflammatory cytokines (Alberti et al., 2017). The immunomodulatory activity of BCP was also explained by an enhanced phagocytic capability, following an increased lysosomal activity and nitric oxide production in macrophages (Carvalho et al., 2017).

Further, BCP exerted a potent immunomodulatory effect by simultaneously inhibiting both Th1 cytokines, including IL-2 and IFN- $\gamma$, and Th2 cytokines, including IL-4, IL-5, and IL-10, in primary splenocytes (Ku and Lin, 2013). Also, BCP is present in many plants, such as Chrysanthemum indicum L. (Hwang and Kim, 2013), Pterodonem arginatus Vogel (Alberti et al., 2014), Myracrodruon urundeuva Allemão (Carvalho et al., 2017), Schizonepeta tenuifolia (Benth.) Briq. (Ng et al., 2018), and copaiba oil (Urasaki et al., 2020), in which it exerts immunomodulatory activity. Taken together, the studies demonstrate that $\mathrm{CB} 2 \mathrm{R}$ play a key role in balancing the immune response and $\mathrm{BCP}$ by activating $\mathrm{CB} 2 \mathrm{R}$, holding promise in the therapeutic modulation of immuneinflammatory changes in patients with SARS-CoV-2 infection.

In COVID-19, the use of immunomodulators is receiving attention and being regarded as a "sub-etiological treatment" in the absence of an effective antiviral drug. Additionally, BCP 


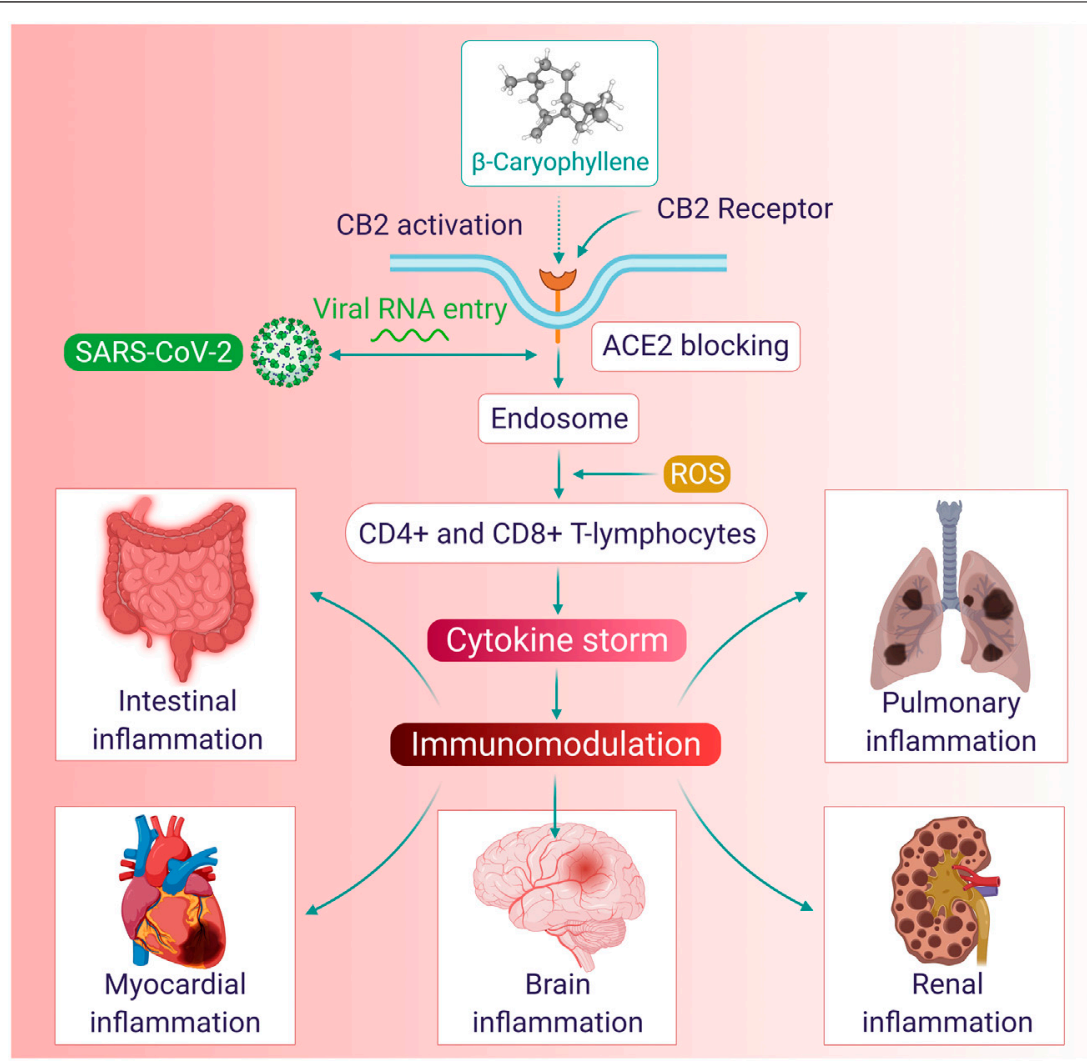

FIGURE 3 | The immunomodulatory mechanisms and organ-protective effects of BCP.

was shown to reduce ACE activity, which may be useful as ACE2 receptors, as the gateways of the virus entry, play a role from the entry of the virus to viremia and from respiratory distress to sepsis (Adefegha et al., 2017; Ajiboye et al., 2019). The immunomodulatory role of BCP is represented in Figure 3. Given the role of immunomodulators on the modulation of the hyperimmune-inflammatory response in COVID-19 patients, BCP may be a potential candidate for modulating immunity in patients at risk of infection and chronic metabolic and/or degenerative diseases, as well as in preventing the development and reducing the severity of COVID-19.

\section{ANTI-INFLAMMATORY PROPERTIES OF BCP}

Cytokines regulate both inflammation and the immunopathology of viral infection. The massive production of proinflammatory cytokines is the key element that leads to an acute systemic hyperinflammatory state, to a cytokine storm syndrome, determining the intensity and severity of symptoms, eliciting the onset of acute respiratory distress, involving the extrapulmonary system, and increasing the risk of multiple organ failure and mortality during SARS-CoV-2 infection
(Allegra et al., 2020). Mounting evidence demonstrates that BCP exerts potent anti-inflammatory properties in all body organs, including the liver, kidneys, brain, heart, pancreas, and blood, and suppresses systemic inflammation by inhibiting proinflammatory cytokines in macrophages and other inflammatory mediators, as well as signaling pathways (Yamaguchi and Levy, 2020). BCP was shown to exhibit a CB2R-dependent anti-inflammatory property by inhibiting lipopolysaccharide/endotoxin (LPS)-induced phosphorylation of kinases ERK1/2 and JNK1/2 in macrophages, since it is recognized as a $\mathrm{CB} 2 \mathrm{R}$ agonist and a dietary cannabinoid (Gertsch et al., 2008). Macrophages in the lungs express CB2R, which, upon further activation by a CB2R agonist, reduced the release of pro-inflammatory cytokines (such as IL-6) and angiogenic factors (Staiano et al., 2016).

Many pathways were shown to be responsible for the antiinflammatory activity in macrophages, including inhibiting the Ras-MAPK pathway, JNK pathway, TNF- $\alpha$ translation, and the inhibition of proinflammatory cytokines, including TNF- $\alpha$ (Gertsch et al., 2008; Rajesh et al., 2008). TNF- $\alpha$ triggers the activation of Ras, p38 MAPK, ERK1/2, SAPK/JNK, HMGB1/ TLR4, and Akt pathways, and ultimately, the expression of proinflammatory cytokines, cellular proliferation, and migration (Gertsch et al., 2008; Rajesh et al., 2008). Additionally, numerous studies have also demonstrated the 
anti-inflammatory effects of BCP by activating CB2R and their subsequent pathways (Youssef et al., 2019). The CB2R-dependent anti-inflammatory effect of $\mathrm{BCP}$ has been demonstrated in inflammatory states of the heart (Meeran et al., 2019), liver (Cho et al., 2015; Arizuka et al., 2017; Varga et al., 2018), intestines (Cho et al., 2015), kidneys (Horváth et al., 2012; Hammad et al., 2018), lungs (Andrade-Silva et al., 2016), brain (Fontes et al., 2017; Yang et al., 2017; Askari et al., 2019; Askari and Shafiee-Nick, 2019), pancreas (Basha and Sankaranarayanan, 2016), urinary bladder (Berger et al., 2019), joints (Rufino et al., 2015; Irrera et al., 2019; D'Ascola et al., 2019), skin (Koyama et al., 2019), oral cavity, and blood (Brito et al., 2019). BCP also showed anti-inflammatory effects mediating histaminergic and arachidonic acid pathways (Oliveira-Tintino et al., 2018). Though, evidence supports that CB2R activation has antiinflammatory effects, it has yet to be targeted to treat human disease.

$\mathrm{BCP}$ is present in many plants, such as Campomanesia phaea (O.Berg) Landrum (Lorençoni et al., 2020), Pterodon pubescens (Benth.) Benth. (Basting et al., 2019), Ocimumm icranthum Willd. (de Pinho et al., 2012), Mosla dianthera (Buch.-Ham. ex Roxb.) Maxim. (Wu et al., 2012), Cordia verbenacea A. DC. (Basting et al., 2019), Duguetia furfuracea (A.St.-Hil.) Saff. (Saldanha et al., 2019), Cinnamomum osmophloeum Kaneh. (Tung et al., 2008), Croton campestris A.St.-Hil., A. Juss. \& Cambess. (Oliveira-Tintino et al., 2018), Pinus spp.(BasholliSalihu et al., 2017), and Copaiba oil (Ames-Sibin et al., 2018), and has been considered responsible for their anti-inflammatory effects by suppressing proinflammatory cytokines and other inflammatory mediators.

\section{ANTIVIRAL PROPERTIES OF BCP}

The role of plant-based natural products are well explored for their antiviral properties and are gaining attention for their therapeutic potential in COVID-19 (Mahmud et al., 2020; ul Qamar et al., 2020). The antiviral role of plant-derived compounds in inhibiting replication and blocking entry of viruses, including coronaviruses, in the host cells has been well reviewed elsewhere (Wen et al., 2007; Dhama et al., 2018; Hensel et al., 2020). The antiviral potential of many plant-derived compounds against SARS-CoV-2 has been recently demonstrated in in silico, in vitro, and in vivo studies (Bahramsoltani and Rahimi, 2020; Basu et al., 2020; Benarba and Pandiella, 2020; Mondal et al., 2020; ul Qamar et al., 2020). Many of the compounds showed targeting of SARS-CoV-2 using bioinformatic tools such as in silico analysis, molecular docking, or molecular farming to enhance the production of recombinant proteins including vaccines and antibodies (Rosales-Mendoza et al., 2020). In search of antiviral compounds, a library of plant-derived constituents containing 32,297 phytochemicals have been screened in molecular docking and results displayed that nine compounds, including myricitrin, methyl rosamarinate, licoleafol, and amaranthin, may curb the activity of $3 \mathrm{CL}^{\text {pro }}$ enzymes in SARS-CoV-2 (ul Qamar et al., 2020). The inhibitory activity on the proteases and other molecular targets should be assessed for specificity, affinity, dose-response, and kinetics in experimental studies. The binding of these compounds limits the availability of the substrate, modifies configuration of active sites, and prevents dimerization, viral entry, and/or viral replication. The role of cannabinoids against virus replication, maturation, transmission, and entry in particular has been demonstrated in in silico and in vitro studies (Khodadadi et al., 2020; Mohammed et al., 2020; Salles et al., 2020; Wang et al., 2020; Raj et al., 2021). It has become apparent that agents which have antiviral properties corroborated with antiinflammatory and immunomodulatory properties are important to target the trinity of infection, inflammation, and immunity in context of COVID-19. To tackle SARS-CoV-2, the identification of viral protease appears as a striking therapeutic target to limit the replication of SARS-CoV-2 and many of the compounds are being investigated for their potential to target replication by inhibiting viral components such as $\mathrm{M}^{\mathrm{pro}}\left(3 \mathrm{CL}^{\mathrm{pro}}\right)$, $\mathrm{PL}^{\text {pro }}$ and spike proteins. The protease of SARS-CoV-2 emerged as an attractive target to inhibit the replication of the virus. Recently, BCP was shown to target SARS-CoV-2 virus via pie-alkyl interactions to PHE 294 of SARS-CoV-2 with an affinity of -7.2 in an in silico docking study (Narkhede et al., 2020).

The antiviral properties of $\mathrm{BCP}$ or $\mathrm{BCP}$-containing plants have been summarized in Table 1. The antiviral properties against herpes simplex virus type 1 (HSV-1) from the essential oils of many plants have been attributed to their chemical constituents, including $\mathrm{BCP}$ (Astani et al., 2011). The $\mathrm{IC}_{50}$ and $\mathrm{TC}_{50}$ for $\mathrm{BCP}$ were found to be 0.25 and $35 \mu \mathrm{g} / \mathrm{ml}$, respectively (Astani et al., 2011). In plaque reduction assays, BCP exerted a concentrationdependent antiviral effect, with a selectivity index (ratio of $\mathrm{TC}_{50} /$ $\mathrm{IC}_{50}$ ) of 140 . BCP showed $98 \%$ reduction in infectivity, comparable to acyclovir, a standard antiviral drug. The authors suggested that $\mathrm{BCP}$ has potential to inactivate the herpes virus and may affect the structure of the virion envelope, which is essential for adsorption or entry into the host cells (Astani et al., 2011). BCP was shown to inhibit both Herpes Simplex Virus-2 (HSV-2) and acyclovir-resistant strain infections with a similar or lower selectivity index, compared to the BCP-rich essential oil of Salvia desoleana Atzei \& V. Picci. However, BCP was not found to inhibit HSV-1 infection (Loizzo et al., 2008; Cagno et al., 2017). The selectivity index value $>1$ suggests that the compound has inhibitory action on viral replication and has low cytotoxicity on the host cells, thus a high selectivity index demonstrates better action of the compound. In the absence of guidelines on acceptability or appropriateness of selectivity index, values greater than 10 are considered better candidates for antiviral actions. The extracts rich in BCP displayed a very high selectivity index that indicates potent antiviral activity with negligible cytotoxicity on the host cells. The therapeutic efficacy and safety may also have different implications and should be taken in account considering the severity of viral infections and its onset, whether acute or chronic. BCP was tested in cell-based assays and showed a selectivity index of 71.1 in inhibiting the replication of the dengue virus (DENV2). $B C P$ acts as a viricidal by interfering with the very early steps of the viral replication cycle and in silico data showed that BCP 
TABLE 1 | The antiviral activities of $\beta$-Caryophyllene (BCP) or BCP containing plants.

\begin{tabular}{|c|c|c|c|}
\hline Sources & BCP (\%) & Viral targets & References \\
\hline Mosla dianthera (Buch. -Ham. ex Roxb.) Maxim & 14.49 & Influenza virus A (IVA) & Wu et al. (2012) \\
\hline Glechon spathulata Benth & 14.2 & Human Herpes Virus Type 1 (HSV-1) & Venturi et al. (2015) \\
\hline Glechon marifolia Benth & 32.2 & HSV-1 & Venturi et al. (2015) \\
\hline Illicium verum Hook.f & - & HSV-1 & Astani et al. (2011) \\
\hline Buddleja cordobensis Griseb & 16.5 & DENV-2, JUNV and HSV-1 & Duschatzky et al. (2005) \\
\hline Cinnamomum zeylanicum Blume & $0.5-6.7$ & Influenza type A (H1N1) & Setzer (2016) \\
\hline Eupatorium patens D. Don ex Hook. and Arn & 14.1 & HSV-1 & García et al. (2003) \\
\hline Gaillardia megapotamica (Spreng.) Baker & 6.7 & DENV-2, JUNV and HSV-1 & Duschatzky et al. (2005) \\
\hline Hyptis mutabilis (Rich.) Briq & 10.9 & Human Herpes Virus Type 2 (HSV-2) & Brand et al. (2015) \\
\hline Jungia polita Griseb. & 8.1 & DENV-2, JUNV and HSV-1 & Duschatzky et al. (2005) \\
\hline Lavandula angustifolia Mill & 5.1 & $\mathrm{H} 1 \mathrm{~N} 1$ & Setzer (2016) \\
\hline Lepechinia vulcanicola J.R.I. Wood & 8.7 & HSV-1, HSV-2 & Brand et al. (2015) \\
\hline Lippia turbinata Griseb. & 6.4 & HSV-1 & García et al. (2003) \\
\hline Melissa officinalis L & 14.2 & HSV-2 & Allahverdiyev et al. (2004) \\
\hline Ocimum campechianum Mill & 13.0 & HSV-2 & Brand et al. (2015) \\
\hline Thymus capitatus (L.) Hoffmanns. and Link & 2.9 & Cytopathogenic murine norovirus & Moussaoui et al. (2013) \\
\hline Thymus vulgaris $L$ & 7.0 & HSV-1 & Schnitzler et al. (2007) \\
\hline Zataria multiflora Boiss. & 3.0 & Real time PCR (H9N2 subtype of AIV) & Shayeganmehr et al. (2018) \\
\hline
\end{tabular}

specifically targets the dengue virus proteins. BCP was also found useful in Epstein-Barr virus-associated diseases. BCP has been recognized in the essential oil of Waldheimia glabra (Decne.) Regel, popularly known as 'Ghaan-Poe', is used for influenza in Tibetan medicine (Manzo et al., 2016; De et al., 2017). The essential oil showed antiviral activity against influenza virus $\mathrm{H} 3 \mathrm{~N} 2$ in an in vitro assay and was found comparable to ribavirin, a standard antiviral drug (Manzo et al., 2016).

Further, the anti-inflammatory activity of essential oil was evidenced by the inhibition of NO production in LPS-stimulated macrophages and was found to be more potent than the standard drug dexamethasone. BCP was found in the essential oil of Teucrium pseudochamaepitys Georgi, an important Tunisian flora element that is used in traditional medicine for its antiviral activity against an enterovirus, Coxsackie 4 (CV-B4), known for causing myocarditis and CNS pathologies (Hammami et al., 2015). The essential oil showed potent antioxidant properties. The BCP-containing essential oil of Glechon spathulata Spreng. and Glechon marifolia Benth. are traditionally used in viral infections for their viricidal activity against HSV-1 strain KOS, VR733 (ATCC), or 29-R (ACV res) (Venturi et al., 2015). The essential oil of Glechon spathulata Spreng. exhibited activity against all strains and Glrchon marifolia Benth. was found to be active against two strains, KOS and VR733. HSV-1 was more susceptible to the oil of Glechon spathulata Spreng. than that of Glechon marifolia Benth. The viral titer was reduced by up to $2 \log _{10}$ for KOS and VR-733 strains. BCP-containing essential oil of Mosla dianthera (Buch.Ham. ex Roxb.) Maxim., a herb popularly used in respiratory illnesses, showed antiviral activity in mice infected with influenza virus A ( Wu et al., 2012). It exerted potent antioxidant, antiinflammatory, and antiviral effects, as evidenced by the reduced serum levels of IFN- $\gamma$ and IL-4, viral titer in the lungs, amelioration of pneumonia, and an increased endogenous antioxidant level in the lung tissues. The findings were suggestive of its possible use in influenza and viral pneumonia (Wu et al., 2012). The essential oil obtained from Fortunella margarita (Lour.) Swingle, commonly known as Kumquats, which belongs to the citrus family, contained BCP and was shown effective against avian influenza-A virus (H5N1). BCPcontaining essential oil of Schizonepeta tenuifolia (Benth.) Briq. was shown to inhibit norovirus replication through the induction of antiviral interferon production during virus replication by inducing the expression of both type I and type II interferons and increasing the transcription of interferon- $\beta$ in infected RAW 264.7 cells via an increased phosphorylation of interferon regulatory factor 3, a critical transcription regulator for type I interferon production (Ng et al., 2018). Very recently, BCP on oral supplementation showed antiviral and immunomodulatory potential in an in vivo viral model of Newcastle disease virus (Hassanin et al., 2020).

In COVID-19 patients, the prevalence of coinfections has been reported and the co-pathogens may be bacteria, such as Streptococcus pneumoniae, Staphylococcus aureus, Klebsiella pneumoniae, Mycoplasma pneumoniae, Chlamydia pneumonia, Legionella pneumophila, and Acinetobacter baumannii, fungi, such as Candida species and Aspergillus flavus, or viruses, such as influenza, coronavirus, rhinovirus/enterovirus, parainfluenza, metapneumovirus, influenza B virus, and human immunodeficiency virus (Lai et al., 2020). Additionally, the antibacterial and antifungal effects of BCP have been reported in a number of studies (Schmidt et al., 2010; Rather et al., 2012; Dahham et al., 2015; Nieto-Bobadilla et al., 2015; Yang et al., 2015; Okoh et al., 2019;). Taken together, the antiviral and antibacterial activities, $\mathrm{BCP}$ may be a promising agent for secondary infections, as well as the viral infections.

\section{ANTIOXIDANT PROPERTIES OF BCP}

Besides the immune-inflammatory changes, macrophages and neutrophils can produce numerous reactive oxygen species (ROS), including $\mathrm{H}_{2} \mathrm{O}_{2},\left(\mathrm{O}_{2}^{-}\right),(\bullet \mathrm{OH})$, which further activates many signaling pathways and the onset of inflammation and cell 
death in many organs, including the lungs (Imai et al., 2008). Oxidative stress and the subsequent activation of NF-kB-toll-like receptor signaling pathways, triggered by viral pathogens such as SARS-CoV-2, are believed to amplify the host inflammatory response that results in acute lung injury (Saleh et al., 2020). Additionally, the hyper inflammatory/oxidative state may lead to the dysfunction of mitochondria, the hub of cellular oxidative homeostasis, and cause platelet damage, which, upon interaction with coagulation cascades, aggravates the clotting events and thrombus formation.

Mitochondrial oxidative stress may contribute to microbiota dysbiosis, altering the coagulation pathways and fueling the inflammatory/oxidative response, leading to a vicious cycle of events (Saleh et al., 2020). Oxidative stress further primes endothelial cells to acquire a pro-thrombotic and proinflammatory phenotype, predisposing patients to thromboembolic and vasculitic events and disseminated intravascular coagulopathy (Panfoli, 2020). Nrf2, a transcription factor which regulates the redox balance and the expression of genes involved in immunity and inflammation, is believed to defend against SARS-CoV-2 (McCord et al., 2020). The suppressed redox status of a cell enhances its susceptibility to oxidative stress, which may lead to cell death and viral release (Khomich et al., 2018). SARS-CoV-2 infections can lead to alterations of the redox balance in infected cells through the modulation of $\mathrm{NAD}^{+}$biosynthesis and PARP function, along with altering the proteasome and mitochondrial function in cells, thereby leading to enhanced cell stress responses that further exacerbate inflammation. ROS production can increase IL-6 production and lipid peroxidation, resulting in cell damage (Nasi et al., 2020). Virus-induced inflammation and oxidative stress could be the common mechanisms responsible for the cardiovascular, pulmonary, renal, and neurological symptoms in COVID-19 patients (Nuzzo and Picone, 2020). BCP was found to exert protective effects in renal cells by suppressing ROS generation, NADPH oxidase $2 / 4$ expression, and by controlling cell proliferation and inflammation by inhibiting proinflammatory cytokines, $\mathrm{Nrf} 2 / \mathrm{HO}-1$ and $\mathrm{NF}-\kappa \mathrm{B} / \mathrm{Nrf} 2$ signaling pathways (Li et al., 2020).

BCP is present in Ocimum sanctum L. (Kamyab and Eshraghian, 2013), Pinus spp.(Xie et al., 2015), Salvia officinalis L. (El-Hosseiny et al., 2016), Citrus limoni (L.) Osbeck (Oboh et al., 2014), Stachys pilifera Benth. (Sadeghi et al., 2020), Pistacia lentiscus L. (Mohamed et al., 2018), Eplingiella fruticose (Salzm. ex Benth.) Harley \& J.F.B. Pastore (Beserra-Filho et al., 2019), Lantana montevidensis (Spreng.) Briq. (de Oliveira et al., 2019), Azadirachta indica A. Juss. (Okoh et al., 2019), Rosmarinus officinalis L. (Mohamed et al., 2016), Aquilaria crassna Pierre ex Lecomte (Dahham et al., 2015), and Copaiaba oil (Ames-Sibin et al., 2018) and has been shown to augment the levels of endogenous antioxidants, exerting ferric reducing properties, a $\mathrm{Fe}^{2+}$ chelation, and radicals scavenging activity in DPPH, FRAP, ORAC, ABTS, $\bullet \mathrm{OH}$, and $\mathrm{NO}$ assays (Oboh et al., 2014; Pant et al., 2014). BCP also enhances tolerance against stress, augments chaperons, and improves the antioxidant power (Srivastava et al., 2016). BCP mitigates the oxidative stress by counteracting ROS generation, inhibiting lipid peroxidation and glutathione depletion, free radical scavenging, and augmenting the endogenous antioxidant defense in the tissues of different organs, such as the heart (Ojha et al., 2016; Baldissera et al., 2017; Meeran et al., 2019), brain (Choi et al., 2013; Ojha et al., 2016; Tian et al., 2016), intestine (Bento et al., 2011), liver (Arizuka et al., 2017; Baldissera et al., 2017; Varga et al., 2018), stomach (Tambe et al., 1996), kidneys (Horváth et al., 2012; Hammad et al., 2018), pancreas (Basha and Sankaranarayanan, 2016), and blood (Youssef et al., 2019), which may aid the protective, as well as the adaptative, responses against viral infections and drugs.

BCP has been shown superior to probucol, a-humulene, a-tocopherol (Calleja et al., 2013), and synthetic CB2R agonist, JWH133 (Klauke et al., 2014). Also, BCP was shown to correct neurobehavior (anxiety, depression, and memory deficit), and neurochemical (oxidative, inflammatory, and neurotrophic factor) alterations in diet-induced obese rats (Youssef et al., 2019). Taken together, it is evident that BCP attenuated the oxidative stress and subsequent inflammation in organ dysfunction and metabolic disorders, favorably modulated redox signaling pathways (Baldissera et al., 2017; Varga et al., 2018), which are akin to the pathophysiology of SARS-CoV-2 infection.

\section{BCP MAY BE PROSPECTIVE IN COVID-19 ASSOCIATED SEPSIS}

SARS-CoV-2 infections may lead to sepsis and to subsequent multi-organ failure. Sepsis involves both the inflammatory response and immune suppression in response to an infection (Mira et al., 2017). CB2R plays a vital role in neutrophil/leukocyte recruitment, thereby suppressing infection and inflammation during sepsis (He et al., 2019). However, CB2R was also shown to contribute to septic immune dysfunction and mortality (Csóka et al., 2009). In a recent review the role of CB2R as a therapeutic target has been suggested based on the reports from preclinical animal models or in vitro cultured cells (He et al., 2019). The authors suggested that due to the lack of clinical evidence and the ambiguous underlying mechanisms, the clinical application of CB2R stimulation in sepsis is yet to be confirmed further (He et al., 2019). In many recent studies specific CB2R synthetic agonists, including HU-308 (Liu et al., 2020), GW405833 (Zhou et al., 2020), JWH133 (Çakır et al., 2020), and natural agonist, BCP (Brito et al., 2019), have been shown to ameliorate lung tissue damage, inhibiting oxidative stress, release of inflammatory mediators, recruitment of leucocytes and bacteremia, and improve survival in different preclinical models of sepsis. CB2R agonists were reported to ameliorate leukocyte adhesion to the endothelium, oxidative stress, systemic inflammatory mediators, microcirculatory dysfunction, bacteremia, and lung injury, along with an improvement in survival in experimental models of sepsis (Sardinha et al., 2014; Toguri et al., 2015). CB2R activation specifically mitigated septic lung injury by suppressing inflammatory mediators and augmenting autophagy (Liu et al., 2014; Liu et al., 2020). In an experimental model of polymicrobial 
sepsis, CB2R activation decreased the histopathological damage in the brain, heart, lungs, and liver by reducing the levels of caspase-3, p-NF- $\mathrm{B}$, TNF- $\alpha$, IL- $1 \beta$, and IL- 6 in these tissues, as well as in the serum, and improved the anti-inflammatory cytokine IL-10 levels (Çakır et al., 2020).

To model sepsis, many of the experimental models rely on LPS-induced macrophages, which involve the activation and release of inflammatory mediators, including cytokines (Brito et al., 2019). BCP was reported to reduce the level of leukocytes, cytokines TNF- $\alpha$, IL-6, IL-12, and IFN- $\gamma$, and increase the levels of IL-4 and IL-5 (Brito et al., 2019). BCP was shown to suppress inflammatory mediators and exert inhibitory effects on macrophages (Tung et al., 2008; Yamaguchi and Levy, 2019; Yamaguchi and Levy, 2020). Although the role of CB2R in sepsis has mixed reports, BCP has been shown to be beneficial in sepsis via $\mathrm{CB} 2 \mathrm{R}$ activation and the off target effects cannot be excluded (Meza and Lehmann, 2018). Additionally, BCP is known to have a better safety profile over synthetic cannabinoids. Given the association of SARS-CoV-2 infections and sepsis-induced lifethreatening organ dysfunction, BCP may be a promising candidate for COVID-19 associated sepsis.

\section{BCP MAY BE PROSPECTIVE IN COVID-19 ASSOCIATED NEUROLOGICAL MANIFESTATIONS}

SARS-CoV-2 is considered to be neurovirulent and neuroinvasive, in parallel with adherence to endothelial cells and cardiomyocytes (Sweid et al., 2020). Ischemic stroke, venous thrombosis, and intracerebral hemorrhage are the reported neurological manifestations of SARS-CoV-2 infection (Jiménez-Ruiz et al., 2020). The pathophysiology of ischemic stroke or cerebral hemorrhage includes an increased level of inflammatory cytokines in the brain, subsequent to the activation of microglia, astrocytes, and adhesion molecules, along with leukocyte recruitment and an impaired blood brain barrier. CB2R are upregulated during the inflammatory activation and $\mathrm{CB} 2 \mathrm{R}$ agonists have been shown to be effective in acute ischemia and hemorrhagic stroke (Capettini et al., 2012).

$\mathrm{BCP}$ has been shown to exert a protective role on neurological deficit and neuroinflammation in experimental models, including middle cerebral artery occlusion induced-cerebral ischemia by suppressing the oxidative stress, inflammatory mediators, apoptosis, and reduction in brain edema, as well as preservation of tight junction proteins and repair of blood brain barrier (Zhang et al., 2017; Tian et al., 2019). BCP exerted its protective effects mediating CB2R activation (Choi et al., 2013) and its associated mechanisms, including the downregulation of TLR4 pathways to suppress inflammation and polarizing microglial phenotype from M1 to M2 (Tian et al., 2019), PI3K/Akt signaling pathway to suppress apoptosis (Zhang et al., 2017), an upregulation of the modulation of AMPK/CREB signaling (Choi et al., 2013), and the upregulation of $\mathrm{Nrf2/HO}-1$ pathway to suppress oxidative stress and apoptosis (Lou et al., 2016).
BCP also attenuated neuronal necrosis, receptor-interaction protein kinase-1 (RIPK1), receptor-interaction protein kinase-3 (RIPK3) expression, and mixed lineage kinase domain-like protein (MLKL) phosphorylation in cerebral ischemia by inhibiting high-mobility group box 1 (HMGB1)-toll-like receptor 4 (TLR4) signaling pathways and proinflammatory cytokines. HMGB1, which is released by macrophages and monocytes in response to high levels of proinflammatory cytokines, plays a critical role in allowing innate immune cells to respond to both infection and injury. After its release, HMGB1 binds to its receptor for an advanced glycation of the endproducts, which further activates MAPK and NF- $\mathrm{B}$, resulting in an overgeneration of various cytokines, causing a massive neutrophil infiltration into the lungs, and subsequent acute lung injury. The agents that target the release of HMGB1 are suggested to be useful in reducing mortality by preventing the progression from respiratory distress to sepsis (Wyganowska-Swiatkowska et al., 2020). Given the protective role of BCP on redox homeostasis and on the immune-inflammatory cascade in acute cerebrovascular disorders, it holds therapeutic promise for neurological manifestations of SARS-CoV-2.

\section{BCP MAY BE PROSPECTIVE IN COVID-19 ASSOCIATED CARDIOVASCULAR CONDITIONS}

SARS-CoV-2 infection has been reported to increase the susceptibility of patients affected by coronary artery disease and risk factors of atherosclerotic cardiovascular disease to develop adverse outcomes and lead to death (Vinciguerra et al., 2020). SARS-CoV-2 mediating ACE2 receptors infect endothelial cells, which regulate inflammation, vasomotor tone, and hemostatic balance. Pathological conditions associated with atherosclerotic progression, such as heart failure, coronary heart disease, hypertension, and diabetes mellitus, are the predictive factors for severity and susceptibility during SARS-CoV-2 infection (Vinciguerra et al., 2020). The pathogenesis involves endothelial dysfunction, altered vasopermeability, and formation of pulmonary microthrombi subsequent to inflammation, hypoxia, oxidative stress, mitochondrial dysfunction, and DNA damage. Patients with preexisting pulmonary vascular diseases also appear to have an increased risk of morbidity and mortality (Potus et al., 2020).

Atherosclerosis is considered as an ideal pathogenetic substrate for high viral replication ability, leading to adverse outcomes, as found in patients with cardiovascular factors. SARSCoV-2 may aggravate atherosclerosis due to an excessive and aberrant plasmatic concentration of cytokines (Vinciguerra et al., 2020). Atherosclerosis involves vascular inflammation, characterized by a narrowed vascular lumen in the entire tunica intima and a reduced elasticity of the arterial walls. CB2R activation mitigated endothelial cell activation, transendothelial migration of monocytes, and monocyte/ neutrophil-endothelial adhesion, and suppressed the proliferation and migration of human coronary vascular smooth muscle cells induced by TNF-a (Rajesh et al., 2007). A 
pneumonia causing pathogen, Chlamydia pneumoniae, provokes atheroma lesions by releasing heat shock proteins, which, by activating Hsp60 on endothelial cells, increase vascular smooth muscle cell proliferation. BCP was found to inhibit Hsp60induced vascular smooth muscle cell proliferation and its potential in atherosclerosis has been suggested (Fukuoka et al., 2004). BCP also ameliorated acute myocardial injury by improving cardiac function, reducing infarct, restoring myocyte enzymes, and suppressing inflammation by inhibiting HSP-60/TLR/MyD88/NFkB signaling pathways (Younis and Mohamed, 2019). BCP was found to counteract drug-induced cardiomyopathy by attenuating inflammation, oxidative stress, and apoptosis by activating CB2R (Meeran et al., 2019). BCP mitigated hypercholesterolemia, dyslipidemia, and vascular inflammation, reduced atherogenic and coronary risk index, and corrected lipid metabolism by inhibiting proatherogenic vascular cell adhesion molecule 1 (VCAM-1) and restoring vascular eNOS/iNOS expression by maintaining the NO levels, mediating the activation of $\mathrm{CB} 2$ and $\mathrm{PPAR}-\gamma$ receptors in a highfat diet and fructose-induced obesity (Baldissera et al., 2017; Harb et al., 2018; Youssef et al., 2019).

Furthermore, in addition to correcting the lipid profile, BCPmediating CB2R-dependent mechanism inhibited leukocyteendothelial attachment, neutrophil recruitment, and macrophage infiltration, inducing VCAM-1 to mediate the JAK2/STAT1/IRF-1 pathway (Zhang et al., 2017). BCP is one of the most important components of Copaiba oil, popularly used in Brazil for respiratory and cardiovascular illnesses. The nanocapsules of copaiba oil were shown to attenuate monocrotalineinduced pulmonary arterial hypertension in rats by counteracting the oxidative stress and inflammation, and by improving the cardiac function (Campos et al., 2017). One of the major clinical features and reasons for death in COVID-19 patients is respiratory distress syndrome, that also leads to acute cardiac injury (Huang et al., 2020). The potential of BCP on pulmonary vasculature is also promising and can be useful in reducing the risk of cardiopulmonary complications. The available studies are clearly suggestive of the therapeutic benefits of BCP in atherosclerosis, acute myocardial infarction, dyslipidemia, obesity, and fatty liver and could be important in preventing the worsening of the condition in COVID-19 patients.

\section{BCP MAY BE PROSPECTIVE IN COVID-19 ASSOCIATED INTESTINAL INFLAMMATION}

BCP was found to reduce the number of enterobacteria in the luminal and mucosal components, improving the clinical course of an intestinal inflammation in the mice model of colitis (NietoBobadilla et al., 2015). BCP ameliorated intestinal inflammation in the animal models by mediating the activation of CB2 and the PPAR- $\gamma$ pathway (Cho et al., 2007; Bento et al., 2011). It suppressed MPO activity and reduced the serum levels of protein and mRNA of IL-6 by 55\% (Cho et al., 2007). IL-6 signaling pathway appears as one of the potential therapeutic targets for COVID-19. BCP also suppressed
$\mathrm{N}$-acetylglucosaminidase activity and the levels of mRNA expression of TNF- $\alpha$, IL- $1 \beta$, IFN- $\gamma$, chemokines, and the activation of extracellular signal-regulated kinase $1 / 2, N F-\kappa B$, I $\mathrm{B}$-kinase $\alpha / \beta$, cAMP response element binding, and the expression of caspase-3 and Ki-67. BCP increased IL-4 levels and forkhead box P3 mRNA expression in the colon (Cho et al., 2007; Bento et al., 2011). In macrophages challenged with LPS, $\mathrm{BCP}$ reduced the levels of cytokines, such as TNF- $\alpha$, keratinocytederived chemokines, and MIP-2.

Recently, in patients infected with SARS-CoV-2, an inflammatory response in the gut is evidenced by diarrhea and increased IL-6 and fecal calprotectin levels, showing the activation of neutrophils (Effenberger et al., 2020). Additionally, diarrhea appears as one of the most frequent symptoms in patients infected with SARS-CoV-2 (D'Amico et al., 2020). Given the role of BCP in suppressing intestinal inflammation (Cho et al., 2007; Bento et al., 2011) and diarrhea (Nieto-Bobadilla et al., 2015), BCP may hold great therapeutic promise for COVID-19.

\section{BCP MAY BE PROSPECTIVE IN COVID-19 ASSOCIATED AIRWAY INFLAMMATION}

In many reports, vaccination of Bacillus Calmette-Guérin (BCG), a live attenuated vaccine of Mycobacterium bovis strain, is believed to provide protection against SARS-CoV-2 infection. BCG vaccination is believed to be associated with the induction of trained immunity, a kind of epigenetic reprogramming of innate immune cell types (Goodridge et al., 2016). In vaccinated individuals, monocytes and/or natural killer cells exhibit an upregulation of surface markers of activation and synthesis of cytokines, such as IL-1 $\beta$, IL-6, IFN- $\gamma$, and TNF- $\alpha$, in response to infection compared to nonvaccinated individuals; this helps in the faster clearance of pathogens, including influenza (Arts et al., 2018). BCP was found to ameliorate pulmonary inflammation in a mice model of Mycobacterium Bovis BCG-induced pulmonary inflammation by suppressing neutrophil accumulation, suppressing CXCL1/KC, $\mathrm{LTB}_{4}$, IL-12, and NO production, and mediating the CB2R activation (Andrade-Silva et al., 2016).

Additionally, BCP was also found to exert spasmolytic effects on the tracheal smooth muscle in the isolated organs (Pinho-daSilva et al., 2012). BCP produced antispasmodic effects on the isolated tracheal smooth muscle of rats by inhibiting voltagedependent L-type $\mathrm{Ca}^{2+}$ channels. BCP did not affect $\mathrm{Ca}^{2+}$ release from the intracellular storage. Further, the inhibitory effect on epithelial COX and a balance between relaxant and constrictor prostanoids exerted by BCP suggested that it may be useful in asthma-like conditions (Pinho-da-Silva et al., 2012). BCP containing essential oil of Croton sonderianus Müll. Arg. was found to exert myorelaxant activity in rat airway smooth muscles, which is suggestive of its potential in bronchospasm (Pinho-daSilva et al., 2010). During viral infections, the activation of selective CB2R by agonists was shown to suppress leukocyte migration into the site of inflammation (Tahamtan et al., 2018). CB2 agonists in HIV-1 infection also reduced infection in 
primary $\mathrm{CD}^{+} \mathrm{T}$ cells, as well as CXCR4-activation-mediated G-protein activity and the phosphorylation of MAPK (Costantino et al., 2012). The CB2 selective property of BCP is reasonably speculated as a basis for its potential to inhibit virus replication, bacterial growth, and to regulate neutrophil recruitment, thus regulating inflammation.

The acute viral respiratory infections may increase the chances of secondary bacterial infections due to a compromised host immune response and thereby worsen the condition. SARS-CoV2 was also reported to cause secondary bacterial infection (Dong et al., 2020). BCP is present in many plants, such as Artemisia capillaris Thunb. (Yang et al., 2015), Juniperus rigida var. hibernica Pshenn. (Meng et al., 2016), Lavandula coronopifolia Poir. (Ait Said et al., 2015), Juglans regia L. (Rather et al., 2012), Mosla dianthera (Buch.-Ham. Ex Roxb.) Maxim. (Wu et al., 2012), Thymbra spicata L. (Saidi et al., 2012), and Lantana camara subsp. glandulosissima (Hayek) R.W. Sanders (Tesch et al., 2011), which have been shown to exert inhibitory activity against respiratory pathogens and many virus, fungi, bacteria, and parasites in experimental studies and in human isolates.

\section{BCP MAY BE PROSPECTIVE IN COVID-19 ASSOCIATED LIVER DYSFUNCTION}

Liver impairment has been reported in patients with SARS-CoV2 infection (Feng et al., 2020; Sun et al., 2020) and it is believed to be due to systemic inflammation caused by a cytokine storm or pneumonia-associated hypoxia, and the drug regimens containing acetaminophen (Zhang et al., 2020). ACE2 receptors in the bile duct epithelial cells are expressed twenty times more than in hepatocytes and this plausibly explains that SARS-CoV-2 infection may cause bile duct epithelial cell damage (Lee et al., 2020). BCP was reported to ameliorate liver fibrosis in a bile duct ligation induced model, suppressing inflammation and apoptotic cell death by mediating the activation of $\mathrm{CB} 2 \mathrm{R}$ (Mahmoud et al., 2014). BCP has also been reported to ameliorate drug induced liver injuries, such as ketoprofeninduced liver injury (Kelany and Abdallah, 2016), carbon tetrachloride-induced liver injury (Calleja et al., 2013), and D-galactosamine and lipopolysaccharide-induced liver failure by suppressing inflammation and mediating TLR4 and RAGE signaling pathways (Cho et al., 2015). BCP was partially attributed to the hepatoprotective effects of many plants, such as Ocimum sanctum L. (holy basil) (Kamyab and Eshraghian, 2013).

SARS-CoV-2 infection also increases vulnerability in patients with non-alcoholic fatty liver disease (NAFLD), a chronic liver disease characterized by hepatic steatosis (fatty liver), inflammation and hepatocyte damage (steatohepatitis), and lipotoxicity (Prins and Olinga, 2020). The expression of ACE2 is increased in cholangiocytes and hepatocytes during chronic liver damage and was increased in a diet-induced experimental model of NAFLD (Prins and Olinga, 2020). Metabolic perturbations, such as obesity, insulin resistance, hyperglycemia, dyslipidemia, and systemic hypertension, which constitute metabolic syndrome, are one of the risk factors of NAFLD (Friedman et al., 2018; Prins and Olinga, 2020). BCP showed a cholesterol-lowering effect by inhibiting the activity of hepatic hydroxy-methylglutaryl coenzyme $\mathrm{A}$ reductase in experimental models of hypercholesterolemia (Arizuka et al., 2017; Baldissera et al., 2017; Harb et al., 2018). Besides correcting the lipid metabolism, BCP also increased high density lipoprotein and attenuated liver injury and fibrosis, restored liver function enzymes and improved antioxidants (Harb et al., 2018).

BCP also attenuated chronic and binge alcohol-induced liver injury and inflammation by attenuating the pro-inflammatory phenotypic ' $\mathrm{M} 1$ ' switch of Kupffer cells and by decreasing the expression of vascular adhesion molecules intercellular adhesion molecule 1, E-selectin, and P-selectin, as well as the neutrophil infiltration, and corrected hepatic metabolic dysregulation (Varga et al., 2018). BCP inhibited palmitateinducible lipid accumulation in human HepG2 hepatocytes by activating AMPK mediating CB2R-dependent $\mathrm{Ca}^{2+}$ signaling pathway (Kamikubo et al., 2016). Mechanistically, BCP regulated hepatic lipid and glucose metabolism by modulating adenosine monophosphate (AMP)-activated protein kinase (AMPK), the main cellular energy sensor (Xu et al., 2018). Considering its hepatoprotective roles, BCP could be promising in conditions of liver injury associated with SARSCoV-2 infection.

\section{BCP MAY BE PROSPECTIVE IN COVID-19 ASSOCIATED RENAL INJURIES}

Acute kidney injury is one of the major complications in patients with SARS-CoV-2 infection (Cheng et al., 2020). ACE2 receptors located on the apical membrane and tubular cells facilitate viral entry and the infection elicits inflammatory responses that cause acute kidney injury (Fanelli et al., 2020; Soleimani, 2020). BCP ameliorated acute kidney injury in experimental models by attenuating renal impairment and tubular injury, suppressing renal inflammatory mediators, oxidative stress, apoptotic cell death, and preserving renal morphology via activation of CB2R (Horváth et al., 2012; Hammad et al., 2018).

BCP is present in many plants, such as Stachys pilifera Benth. (Sadeghi et al., 2020), Salvia officinalis L. (Koubaa et al., 2019), Rosmarinus officinalis L. (Mohamed et al., 2016), and Pluchea indica (L.) Less. (Sirichaiwetchakoon et al., 2020), and has been shown to be responsible for the renoprotective effects against drug induced-acute kidney injury, as well as diabetic and chronic kidney diseases, by restoring the renal function and suppressing oxidative stress, inflammation, and apoptosis. BCP also attenuated renal inflammation and oxidative stress by regulating $\mathrm{NF}-\kappa \mathrm{B} / \mathrm{Nrf2}$ signaling pathways in diabetic kidney diseases ( $\mathrm{Li}$ et al., 2020). Given the increased risk of renal dysfunction in COVID-19 and the worsening of conditions in patients with chronic kidney or diabetic kidney disease, BCP may be a valuable candidate in preventing renal dysfunction in patients with COVID-19. 


\section{TISSUE PROTECTIVE EFFECTS OF BCP MAY BE PROSPECTIVE IN COVID-19 ASSOCIATED ORGAN INJURIES}

Besides the lungs, the main site of virus entry and injury, SARSCoV-2 infection may also affect other organs or organ systems, including the hepatic, renal, neurological, cardiovascular, musculoskeletal, gastrointestinal, hematological, olfactory, gustatory, ophthalmic, and cutaneous systems (Lai et al., 2020). Cardiac manifestations of SARS-CoV-2 involve endothelial damage, an altered lipid profile, endotoxemia, catecholamine, hypoperfusion, unstable hemodynamics, and drug-induced toxicity. BCP showed protective effects against catecholamine-induced myocardial injury and drug-induced cardiotoxicity by improving hemodynamics and alleviating endotoxemia by suppressing inflammation, oxidative stress, and apoptosis via activation of CB2R (Meeran et al., 2019).

The clinical manifestations of COVID-19 range from mild to severe with extensive involvement of the lungs, from pneumonia to ARDS, acute liver injury, acute cardiac injury, and neurological manifestations that may lead to multi-organ failure with a poor prognosis (Wang et al., 2020; Zhu et al., 2020). Severe lung disease with extensive alveolar damage and progressive respiratory failure leads to deadly outcomes (Yang et al., 2020). The fatalities are higher in older people with cardiometabolic diseases, cancer, immunocompromised patients, or patients with comorbidities. BCP was found to ameliorate renal dysfunction in acute and chronic kidney injury and diabetic kidneys.

BCP was found to be effective in liver failure by suppressing liver necrosis, fibrosis, and restoring liver function, mediating $\mathrm{CB} 2 \mathrm{R}$ activation. $\mathrm{BCP}$ has been shown to be neuroprotective in models of cerebral ischemia, dopaminergic neurodegeneration, seizures, dementia, neurocognitive disorders, depression, anxiety, and encephalitis. BCP improved systemic inflammation and oxidative status with no hepatotoxicity, as with nonsteroidal anti-inflammatory drugs (Ames-Sibin et al., 2018). It also reduced nausea, epigastric pain, and diarrhea, and improved gastrointestinal activity (Patra et al., 2010). BCP was also found to promote wound healing by modulating numerous signaling pathways (Parisotto-Peterle et al., 2020). Hematological abnormalities, including lymphopenia and leukopenia, have been reported in COVID-19 patients (Ding et al., 2020). The occurrence of leukopenia induced by chemotherapeutic drugs in an experimental model has been shown to be prevented by BCP (Campos et al., 2015).

Upon oral administration, BCP was found to be bioavailable in almost every organ, including the liver, kidneys, heart, lungs, and blood (Pant et al., 2019). BCP was shown to modulate stress-related genes, provide resistance against stress, improve life span, reduce ageing, and was considered one of the best adaptogenic compounds to enhance the tolerance against stress. The interactions between phytocannabinoids and terpenoids have been suggested to exert synergy for the therapeutic benefits in pain, inflammation, depression, anxiety, addiction, epilepsy, cancer, and microbial infections (Russo, 2011). Given the impact of COVID-19 on organ functions and considering the organ-protective effect of $\mathrm{BCP}$, it is reasonable to hypothesize that the organ-protective activity of BCP will be beneficial in COVID-19.

\section{SAFETY AND TOXICITY OF BCP}

The United States Food and Drug Administration (USFDA) included BCP in the list of compounds regarded as Generally Recognized as Safe (GRAS) for its use as an additive and preservative in food products and beverages. BCP was shown to modulate the expression of drug metabolizing enzymes (phase I and II) in cell lines, rodents, and human liver microsomes, which may influence the bioavailability and efficacy of concomitantly administered drugs (Ambrož et al., 2019). BCP was shown to have a chemopreventive effect and is free from genotoxicity (Álvarez-González et al., 2014), mutagenicity (Di Giacomo et al., 2016), and clastogenicity (Di Sotto et al., 2010).

BCP exerted synergistic and/or additive actions with many drugs including azithromycin (Zhang et al., 2020), atovaquone (Zhang et al., 2020), metaxolone (Yamaguchi and Levy, 2020), imipramine (Askari et al., 2019), fluoxetine (Askari and ShafieeNick, 2019), docosahexaenoic acid (Brito et al., 2019), curcumin (Srivastava et al., 2016; D’Ascola et al., 2019), baicalein (Yamaguchi and Levy, 2016), catechin (Yamaguchi and Levy, 2016) and vitamins, which are suggested to be useful for repurposing for COVID-19. In many experimental studies, BCP was found to be better than the standard modern drugs such as phenylbutazone (Basile et al., 1988), probucol (Calleja et al., 2013), tocopherol (Calleja et al., 2013), ribavirin (Wu et al., 2012), atorvastatin (Campos et al., 2015), glibenclamide (Basha and Sankaranarayanan, 2016), and pioglitazone (Youssef et al., 2019). BCP delivered by inhalation was found to be bioavailable in the saliva and appears safe and tolerable (Tarumi and Shinohara, 2020). BCP was convincingly shown to mitigate drugs or xenobiotics-induced organ injuries; for example, it was found to improve the therapeutic efficacy of immunosuppressive drugs and reduce their side effects, such as myelosuppression and hepatotoxicity in experimental arthritis (El-Sheikh et al., 2019). BCP studied at the therapeutic doses was found devoid of organ toxicity in the experimental studies.

\section{CLINICAL EFFICACY AND SAFETY OF BCP}

BCP administered orally at a dose of $126 \mathrm{mg} /$ day was evaluated in patients with peptic ulcer in a randomized double-blind, placebocontrolled trial (Shim et al., 2019). BCP improved dyspepsia symptoms by reducing Helicobacter pylori infections, improving nausea and epigastric pain, and mediating the inhibition of proinflammatory cytokines (Shim et al., 2019). BCP (3\%) was evaluated in nineteen women for 20 min using an odor exposure device and was found to improve the libido and vaginal sensation during intercourse in women by improving the salivary 
testosterone concentrations with no effect on estrogen (Tarumi and Shinohara, 2020).

BCP was administered to diabetes patients with diabetesrelated complications; painful distal symmetric polyneuropathy was found to relieve polyneuropathy with an increased amplitude and a reduction of pain, with good tolerance and no adverse effects (Semprini et al., 2018). Recently, in a placebo-controlled clinical study, patients with hand arthritis applied BCPcontaining copaiba oil topically and BCP was found to be safe, well tolerated, and beneficial in reducing pain and inflammation (Bahr et al., 2018).

\section{DOSAGE FORMS AND PHARMACEUTICAL DEVELOPMENT OF BCP}

Many formulations containing BCP have been developed, including Amukkara Choornam (Patra et al., 2010), CIN-102, a coated pellets and matrix mini-tablet (Nieto-Bobadilla et al., 2015), and PipeNig ${ }^{\circledR}$-FL, a high standardized content of BCP (Geddo et al., 2019). BCP is highly lipophilic, less soluble in water and, upon exposure to air, it easily oxidizes. To overcome its low bioavailability, many novel drug delivery systems have been developed. Various kinds of formulations, such as liposomes, nanoemulsions, nanofibers, microemulsions, nanoparticles, micelles, phospholipid complexes, nanocarriers, nanocomposites, hydrogels, and matrix formulations using cyclodextrin, have been developed to enhance the solubility, stability, and release pattern of BCP (Santos et al., 2018). Novel formulations will pave the way for the pharmaceutical development of BCP and may aid in improving its clinical usage.

\section{LIMITATIONS}

Since the emergence of COVID-19, a significant number of natural products, including plant extracts and phytochemicals, have been proposed for their possible use as a preventive agent or as an adjuvant in COVID-19 (Asif et al., 2020; Boukhatem and Setzer, 2020; da Silva et al., 2020; Diniz et al., 2021). Though, given their pleiotropic and immunomodulatory nature, the role of phytocannabinoids are reasonably suggested useful, but caution should be exercised. The potential application of cannabinoids in COVID-19 management can't be overlooked until proof-of-concept studies become available (Pastor et al., 2020; Anil et al., 2021). The cannabinoids shown to possess potent immunomodulatory, anti-inflammatory, and antimicrobial properties are proposed for their use in COVID-19. However, few of the phytocannabinoids have been screened in molecular docking studies for their potential activity against viral targets using the in-silico tools. The role of phytocannabinoids is believed to be delicate given their action on inflammation and immune modulation and the possibility of the unfavorable effects in acute infection due to risk of immunosuppression (Sexton, 2020). Among numerous cannabinoids, BCP has been shown to be more convincing in terms of its immunomodulatory, anti-inflammatory, and antiviral effects. BCP is one of the main compounds identified in a large number of dietary plants and is widely accessible and well-studied for its therapeutic benefits. However, the safety and efficacy of BCP still needs to be established in preclinical and clinical trials for its evidence-based use and application in humans. BCP is a functional agonist of CB2R and devoid of psychotropic effects, which makes BCP a fascinating candidate molecule for further investigation.

A majority of the experimental research carried out on the therapeutic benefits of phytochemicals are based on ethnopharmacological usage of the particular plant rich in these. Many have also been evaluated for their antiviral properties in addition to their anti-inflammatory and immunoregulatory roles in numerous immune-related disease models. Since the emergence of COVID-19, the repurposing of drugs began first with target identification and continues to be used in the screening of druggable agents against viral infections. It is noteworthy to state that until recent years, the antiviral potential of natural products were shown to be effective in in vitro studies, whereas the SARS-CoV emerged in 2003 (Kim et al., 2014; Park et al., 2017). But none of them have been evaluated meticulously enough to translate their effects to humans despite their potential efficacy in preclinical studies. This is due to many reasons, including the lack of an integrated approach. A recent report suggested that if an integrated and rigorous approach could have been followed since the emergence of SARS-CoV, we may have progressed to clinical studies and developed some useful agents in the process of drug discovery and development, which involves the testing of druggable compounds from laboratory to clinics (Pandey et al., 2020). It can be proposed that the phytochemicals should be investigated and validated in the preclinical models of COVID-19 despite strong evidence for their anti-inflammatory, immunomodulatory, and antiviral properties.

In the present manuscript, the possible role of BCP in COVID19 has been proposed based on the previously reported potent pharmacological activity of BCP against infection, inflammation, and immunity in experimental models of human diseases other than SARS-CoV-2. Many authors proposed the hypotheses that CB2R, an important constituent in endocannabinoid system, may play a role in targeting the trinity of infection, inflammation, and immune dysregulation (Nagoor Meeran et al., 2020). Given the role of $\mathrm{CB} 2 \mathrm{R}$ activation in attenuating inflammation, viral replication, and favorable modulation of immune systems, $\mathrm{BCP}$ endowed with the $\mathrm{CB} 2 \mathrm{R}$ selective agonist property has been pharmacologically reasoned to be a candidate for its possible use as preventive agent or therapeutic adjunct in COVID-19. There are reports of long-term complications in some patients even after recovery from COVID-19. Thus, given the tissue protective effects and effect on numerous tissues remodeling effects, BCP could be a candidate to be investigated for possible use in improving prognosis and combating the long-term complications in COVID-19. Taking into consideration the safety of BCP in humans, dietary use, and efficacy of BCP in various disease models in experimental studies, $\mathrm{BCP}$ may be a valuable agent to be investigated further for COVID-19. 
The available reports clearly demonstrate that the progression and complications of COVID-19 involves cytokine storm, therefore, cannabinoids activating CB2R may inhibit cytokine storm due to their additional organ-protective effects. However, until now there has been no clear evidence available on the antiviral activity of BCP on SARS-CoV-2. There is no preclinical or clinical data available on whether BCP can protect against COVID-19 or may be useful in treatment of COVID-19. The recent availability of animal models could be important in evaluating its preclinical efficacy. There is a lack of clinical data and rigorous pharmacokinetics in humans. Therefore, preclinical evaluation, including duration of use and dose, is suggested. The safety and interaction with concomitant drugs, as well as the heterogeneity of the target population, should also be considered before the possible use of BCP whether in prevention or as adjunct treatment. Nonetheless, there is an opportunity for further investigation to investigate the possible use against COVID-19. Considering the safety evidenced in numerous experimental and few clinical studies, further studies are encouraged to recommend the clinical usage and pharmaceutical development of BCP.

\section{CONCLUSION}

$\mathrm{BCP}$ is a unique molecule in various ways, such as being dietary, devoid of psychotropic effects, possessing negligible toxicity, wide availability in plants, oral bioavailability, a druggable property, and functional receptor selectivity. BCP interacts or binds to different receptors, including CB2, PPAR- $\alpha$, and PPAR- $\gamma$, opioid, histaminergic, TRPV, and TLR, and has enzyme inhibitory activities, including amylase, lipase, a-glucosidase, HMG-CoA reductase, acetylcholinesterase, secretase, cyclooxygenase, and nitric oxide synthase. Taken together, the receptor selectivity made it a distinctive candidate with a pharmacological rationale for pharmaceutical development, more than an antioxidant molecule, which is common with natural products-based nutraceuticals. Integrating the potent anti-inflammatory, immunomodulator, and antiviral properties of BCP and its potential benefits in pathological features of cardiovascular, neurological, gastrointestinal, hematological, renal, ocular, and cutaneous systems, which are the common accompaniments of SARS-CoV-2 infection, the benefits of BCP and plants rich in BCP may be important for COVID19. The candidature of BCP in COVID-19 treatment may appear somewhat speculative but cannot be overlooked as it possesses favorable physiochemical and druggable properties

\section{REFERENCES}

Adefegha, S. A., Olasehinde, T. A., and Oboh, G. (2017). Essential Oil Composition, Antioxidant, Antidiabetic and Antihypertensive Properties of Two Afromomum Species. J. Oleo Sci. 66, 51-63. doi:10.5650/jos. ess 16029

Ait Said, L., Zahlane, K., Ghalbane, I., El Messoussi, S., Romane, A., Cavaleiro, C., et al. (2015). Chemical Composition and Antibacterial Activity of Lavandula with dietary use. However, the suggestion on the possible use of BCP in COVID-19 remains inconclusive until the in-silico observations could be confirmed in the experimental studies and further proof of the concept studies.

The polypharmacological properties, including receptor selectivity provide rationale and its drug-like properties, provide more realism for its future in drug discovery and development. Additionally, the antioxidant, anti-stress, and longevity potential provide a nutritional basis of its use to boost the immunity and suppress overt oxidative stress and subsequent hyperinflammatory states. Considering the recognition of safety status by USFDA and its favorable pharmacokinetic and physicochemical properties, BCP itself or plants containing a high amount of BCP may be important for nutritional or dietary usage. BCP and the plants containing $\mathrm{BCP}$ as a major ingredient may be candidates for developing novel antiviral and immunomodulator therapies for coronaviruses. However, further research is needed to address novel drug discovery employing the chemical scaffold or pharmacophores of BCP. The natural dietary availability and CB2 receptors mediated functional properties and selectivity are suggestive of developing BCP-based nutraceuticals and pharmaceuticals as candidate compounds for COVID-19 and other coronavirus diseases. The opinion of the authors on possible candidature for possible use of BCP in COVID-19 is solely based on available literature on the effects of BCP against infection, immunity, and inflammation in corroboration with the in-silico studies. The authors do not promote the use of BCP in any form for COVID-19 until clear evidence becomes available from proof of the concept studies.

\section{AUTHOR CONTRIBUTIONS}

SO conceptualized the study and hypothesis. NJ, CS, HH, and HJ performed literature search. NJ draw the schemes and drafted the artwork. SA drafted the tables. NJ, CS, HJ, CP, SG, and SO contributed significantly in editing the manuscript. All authors read, edited and approved the manuscript.

\section{ACKNOWLEDGMENTS}

The authors are grateful to the United Arab Emirates University, UAE for providing facilities.

Coronopifolia Essential Oil against Antibiotic-Resistant Bacteria. Nat. Prod. Res. 29, 582-585. doi:10.1080/14786419.2014.954246

Ajiboye, B. O., Ojo, O. A., Fatoba, B., Afolabi, O. B., Olayide, I., Okesola, M. A., et al. (2019). In Vitro Antioxidant and Enzyme Inhibitory Properties of the n-Butanol Fraction of Senna podocarpa (Guill. And Perr.) Leaf. J. Physiol. Pharmacol. 31. doi:10.1515/jbcpp-2019-0123

Alberti, T. B., Marcon, R., Bicca, M. A., Raposo, N. R. B., Calixto, J. B., and Dutra, R. C. (2014). Essential Oil from Pterodon emarginatus Seeds Ameliorates Experimental Autoimmune Encephalomyelitis by 
Modulating Th1/Treg Cell Balance. J. Ethnopharmacol. 155, 485-494. doi:10.1016/j.jep.2014.05.044

Alberti, T. B., Barbosa, W., Vieira, J., Raposo, N., and Dutra, R. (2017). (-)- $\beta$-Caryophyllene, a CB2 Receptor-Selective Phytocannabinoid, Suppresses Motor Paralysis and Neuroinflammation in a Murine Model of Multiple Sclerosis. IJMS 18, 691. doi:10.3390/ijms18040691

Alferink, J., Schmidt, K., Ruland, C., Lundt, R., Kemter, A., Dlugos, A., et al. (2016). Cannabinoid Receptor 2 Modulates Susceptibility to Experimental Cerebral Malaria through a CCL17-Dependent Mechanism. J. Biol. Chem. 291, 19517-19531. doi:10.1074/jbc.M116. 746594

Allahverdiyev, A., Duran, N., Ozguven, M., and Koltas, S. (2004). Antiviral Activity of the Volatile Oils of Melissa Officinalis L. Against Herpes Simplex Virus Type2. Phytomedicine 11, 657-661. doi:10.1016/j.phymed.2003.07.014

Allegra, A., Gioacchino, M. D., Tonacci, A., Musolino, C., and Gangemi, S. (2020). Immunopathology of SARS-CoV-2 Infection: Immune Cells and Mediators, Prognostic Factors, and Immune-Therapeutic Implications. IJMS 21, 4782. doi:10.3390/ijms 21134782

Álvarez-González, I., Madrigal-Bujaidar, E., and Castro-García, S. (2014). Antigenotoxic Capacity of Beta-Caryophyllene in Mouse, and Evaluation of Its Antioxidant and GST Induction Activities. J. Toxicol. Sci. 39, 849-859. doi:10.2131/jts.39.849

Aly, E., Khajah, M. A., and Masocha, W. (2019). $\beta$-Caryophyllene, a CB2-ReceptorSelective Phytocannabinoid, Suppresses Mechanical Allodynia in a Mouse Model of Antiretroviral-Induced Neuropathic Pain. Molecules 25, 106. doi:10.3390/molecules 25010106

Ambrož, M., Šmatová, M., Šadibolová, M., Pospíšilová, E., Hadravská, P., Kašparová, M., et al. (2019). Sesquiterpenes $\alpha$-Humulene and $\beta$-Caryophyllene Oxide Enhance the Efficacy of 5-fluorouracil and Oxaliplatin in Colon Cancer Cells. Acta Pharm. 69, 121-128. doi:10.2478/ acph-2019-0003

Ames-Sibin, A. P., Barizão, C. L., Castro-Ghizoni, C. V., Silva, F. M. S., SáNakanishi, A. B., Bracht, L., et al. (2018). $\beta$-Caryophyllene, the Major Constituent of Copaiba Oil, Reduces Systemic Inflammation and Oxidative Stress in Arthritic Rats. J. Cell. Biochem. 119, 10262-10277. doi:10.1002/jcb. 27369

Andrade-Silva, M., Correa, L. B., Candéa, A. L. P., Barbosa, H. S., Rosas, E. C., Henriques, M. G., et al. (2016). The Cannabinoid 2 Receptor Agonist $\beta$-Caryophyllene Modulates the Inflammatory Reaction Induced by Mycobacterium Bovis BCG by Inhibiting Neutrophil Migration. Inflamm. Res. 65, 869-879. doi:10.1007/s00011-016-0969-3

Anil, S. M., Namdar, D., Belausov, E., Shoval, I., Mani, K. A., Mechrez, G., et al. (2021). Cannabis Compounds Exhibit Anti-inflammatory Activity In Vitro in COVID-19-Related Inflammation in Lung Epithelial Cells and Proinflammatory Activity in Macrophages. Sci. Rep. 11, 11. doi:10.1038/s41598021-81049-2

Arizuka, N., Murakami, T., and Suzuki, K. (2017). The Effect of $\beta$-Caryophyllene on Nonalcoholic Steatohepatitis. J. Toxicol. Pathol. 30, 263-273. doi:10.1293/ tox.2017-0018

Arts, R. J. W., Wang, S.-Y., Oosting, M., Kumar, V., Xavier, R. J., Wijmenga, C., et al. (2018). BCG Vaccination Protects Against Experimental Viral Infection in Humans Through the Induction of Cytokines Associated With Trained Immunity. Cell Host Microbe 23, 89-100. doi:10.1016/j.chom.2017.12.010

Asif, M., Saleem, M., Saadullah, M., Yaseen, H. S., and Al Zarzour, R. (2020). COVID-19 and Therapy With Essential Oils Having Antiviral, Antiinflammatory, and Immunomodulatory Properties. Inflammopharmacology 28, 1153-1161. doi:10.1007/s10787-020-00744-0

Askari, V. R., and Shafiee-Nick, R. (2019). Promising Neuroprotective Effects of $\beta$-Caryophyllene Against LPS-Induced Oligodendrocyte Toxicity: A Mechanistic Study. Biochem. Pharmacol. 159, 154-171. doi:10.1016/j.bcp. 2018.12.001

Askari, V. R., and Shafiee-Nick, R. (2019). The Protective Effects of $\beta$-Caryophyllene on LPS-Induced Primary Microglia M1/M2 Imbalance: A Mechanistic Evaluation. Life Sci. 219, 40-73. doi:10.1016/j.lfs.2018.12.059

Askari, V. R., Baradaran Rahimi, V., Tabatabaee, S. A., and Shafiee-Nick, R. (2019). Combination of Imipramine, A Sphingomyelinase Inhibitor, and $\beta$-Caryophyllene Improve Their Therapeutic Effects on Experimental
Autoimmune Encephalomyelitis (EAE). Int. Immunopharmacol. 77, 105923. doi:10.1016/j.intimp.2019.105923

Astani, A., Reichling, J., and Schnitzler, P. (2011). Screening for Antiviral Activities of Isolated Compounds From Essential Oils. Evid.-Based Complementary Altern. Med. 2011, 1-8. doi:10.1093/ecam/nep187

Bahr, T., Allred, K., Martinez, D., Rodriguez, D., and Winterton, P. (2018). Effects of a Massage-like Essential Oil Application Procedure Using Copaiba and Deep Blue Oils in Individuals With Hand Arthritis. Complement. Therap. Clin. Pract. 33, 170-176. doi:10.1016/j.ctcp.2018.10.004

Bahramsoltani, R., and Rahimi, R. (2020). An Evaluation of Traditional Persian Medicine for the Management of SARS-CoV-2. Front. Pharmacol. 11, 571434. doi:10.3389/fphar.2020.571434

Baldissera, M. D., Souza, C. F., Grando, T. H., Doleski, P. H., Boligon, A. A., Stefani, L. M., et al. (2017). Hypolipidemic Effect of $\beta$-Caryophyllene to Treat Hyperlipidemic Rats. Naunyn-Schmiedeberg's Arch. Pharmacol. 390, 215-223. doi:10.1007/s00210-016-1326-3

Baldissera, M. D., Souza, C. F., Grando, T. H., Stefani, L. M., and Monteiro, S. G. (2017). $\beta$-Caryophyllene Reduces Atherogenic Index and Coronary Risk Index in Hypercholesterolemic Rats: The Involvement of Cardiac Oxidative Damage. Chem.-Biol. Interact. 270, 9-14. doi:10.1016/j.cbi.2017.04.008

Basha, R. H., and Sankaranarayanan, C. (2016). $\beta$-Caryophyllene, A Natural Sesquiterpene Lactone Attenuates Hyperglycemia Mediated Oxidative and Inflammatory Stress in Experimental Diabetic Rats. Chem.-Biol. Interact. 245, 50-58. doi:10.1016/j.cbi.2015.12.019

Basholli-Salihu, M., Schuster, R., Hajdari, A., Viernstein, H., Mustafa, B., Mueller, M., et al. (2017). Phytochemical Composition, Anti-inflammatory Activity and Cytotoxic Effects of Essential Oils From Three Pinus Spp. Pharm. Biol. 55, 1553-1560. doi:10.1080/13880209.2017.1309555

Basile, A. C., Sertié, J. A., Freitas, P. C., and Zanini, A. C. (1988). Anti-inflammatory Activity of Oleoresin From Brazilian Copaifera. J. Ethnopharmacol. 22, 101-109. doi:10.1016/0378-8741(88)90235-8

Bassaganya-Riera, J., Song, R., Roberts, P. C., and Hontecillas, R. (2010). PPAR- $\gamma$ Activation as an Anti-inflammatory Therapy for Respiratory Virus Infections. Viral Immunol. 23, 343-352. doi:10.1089/vim.2010.0016

Basting, R. T., Spindola, H. M., Sousa, I. M., Trigo, J. R., de Carvalho, J. E., and Foglio, M. A. (2019). Pterodon Pubescens and Cordia Verbenacea Association Promotes a Synergistic Response in Antinociceptive Model and Improves the Anti-inflammatory Results in Animal Models. Biomed. Pharmacother. 112, 108693. doi:10.1016/j.biopha.2019.108693

Basu, A., Sarkar, A., and Maulik, U. (2020). Molecular Docking Study of Potential Phytochemicals and Their Effects on the Complex of SARS-CoV2 Spike Protein and Human ACE2. Sci. Rep. 10, 10. doi:10.1038/s41598-020-74715-4

Benarba, B., and Pandiella, A. (2020). Medicinal Plants as Sources of Active Molecules Against COVID-19. Front. Pharmacol. 11, 1189. doi:10.3389/ fphar.2020.01189

Bento, A. F., Marcon, R., Dutra, R. C., Cola, M., Pereira Leite, D. F., Calixto, J. B., et al. (2011). $\beta$-Caryophyllene Inhibits Dextran Sulfate Sodium-Induced Colitis in Mice Through CB2 Receptor Activation and PPAR $\gamma$ Pathway. Am. J. Pathol. 178, 1153-1166. doi:10.1016/j.ajpath.2010.11.052

Berger, G., Chinnadurai, A., Westhofen, R., Hagn, G., Cox, A., Kelly, M., et al. (2019). Experimental Cannabinoid 2 Receptor Activation by Phyto-Derived and Synthetic Cannabinoid Ligands in LPS-Induced Interstitial Cystitis in Mice. Molecules 24, 4239. doi:10.3390/molecules24234239

Beserra-Filho, J. I. A., Santos, J. R., de Oliveira-Melo, A. J., Menezes, P. D. P., Duarte, M. C., de Souza Araújo, A. A., et al. (2019). Eplingiella Fruticosa Leaf Essential Oil Complexed With $\beta$-Cyclodextrin Produces a Superior neuroprotective and Behavioral Profile in a Mice Model of Parkinson's Disease. Food Chem. Toxicol. 124, 17-29. doi:10.1016/j.fct. 2018.11 .056

Boukhatem, M. N., and Setzer, W. N. (2020). Aromatic Herbs, Medicinal PlantDerived Essential Oils, and Phytochemical Extracts as Potential Therapies for Coronaviruses: Future Perspectives. Plants 9, 800. doi:10.3390/ plants 9060800

Brand, Y. M., Roa-Linares, V. C., Betancur-Galvis, L. A., and Stashenko, E. (2015). Antiviral Activity of Colombian Labiatae and Verbenaceae Family Essential Oils and Monoterpenes on Human Herpes Viruses. J. Essent. Oil Res. 28, 130-137. doi:10.1080/10412905.2015.1093556 
Brito, L. F., Oliveira, H. B. M., Júnior, M. N. S., Souza, E. P., Souza Nascimento, F., Amorim, A. T., et al. (2019). Anti-Inflammatory Activity of $\beta$-Caryophyllene Combined With Docosahexaenoic Acid in a Model of Sepsis Induced by Staphylococcus aureus in Mice. J. Sci. Food Agric. 99, 5870-5880. doi:10. 1002/jsfa. 9861

Buckley, N. E., McCoy, K. L., Mezey, E., Bonner, T., Zimmer, A., Felder, C. C., et al. (2000). Immunomodulation by Cannabinoids is Absent in Mice Deficient for the Cannabinoid CB(2) Receptor. Eur. J. Pharmacol. 396, 141-149. doi:10.1016/ s0014-2999(00)00211-9

Byrareddy, S. N., and Mohan, M. (2020). SARS-CoV2 Induced Respiratory Distress: Can Cannabinoids Be Added to Anti-viral Therapies to Reduce Lung Inflammation? Brain Behav. Immun. 87, 120-121. doi:10.1016/j.bbi. 2020.04.079

Cabral, G. A., Ferreira, G. A., and Jamerson, M. J. (2015). Endocannabinoids and the Immune System in Health and Disease. Handbook Exp. Pharmacol. 231, 185-211. doi:10.1007/978-3-319-20825-1_6

Cagno, V., Ballero, M., Civra, A., Donalisio, M., Bicchi, C., Lembo, D., et al. (2017). In Vitro Anti-Herpes Simplex Virus-2 Activity of Salvia desoleana Atzei \& V. Picci Essential Oil. PLOS ONE 12, e0172322. doi:10.1371/journal.pone.0172322

Çakır, M., Tekin, S., Okan, A., Çakan, P., and Doğanyiğit, Z. (2020). The Ameliorating Effect of Cannabinoid Type 2 Receptor Activation on Brain, Lung, Liver and Heart Damage in Cecal Ligation and Puncture-Induced Sepsis Model in Rats. Int. Immunopharmacol. 78, 105978. doi:10.1016/j.intimp.2019. 105978

Calleja, M. A., Vieites, J. S., Montero-Meléndez, T., Torres, M. I., Faus, M. J., Gil, A., et al. (2013). The Antioxidant Effect of $\beta$-Caryophyllene Protects Rat Liver From Carbon Tetrachloride-Induced Fibrosis by Inhibiting Hepatic Stellate Cell Activation. Br. J. Nutr. 109, 394-401. doi:10.1017/S0007114512001298

Campos, M. I., CamposVieira, C. N., and Aarestrup, B. J. V. (2015). Atorvastatin and Trans-Caryophyllene for the Prevention of Leukopenia in an Experimental Chemotherapy Model in Wistar Rats. Mol. Clin. Oncol. 3, 825-828. doi:10.3892/ mco.2015.544

Campos, C., de Castro, A. L., Ortiz, V. D., Barboza, T. E., Pereira, C., Apel, M., et al. (2017). Effect of Free and Nanoencapsulated Copaiba Oil on MonocrotalineInduced Pulmonary Arterial Hypertension. J. Cardiovasc. Pharmacol. 69, 79-85. doi:10.1097/FJC.0000000000000442

Capettini, L. S. A., da SilvaSavergnini, R. F., Santos, R. A. S., Mach, F., and Montecucco, F. (2012). Update on the Role of Cannabinoid Receptors After Ischemic Stroke. Mediators Inflamm. 2012, 1-8. doi:10.1155/2012/824093

Carvalho, C. E. S., Carvalho, T. P., Moura, A. K. S., Rodrigues, K. A. F., Carneiro, S. M. P., Arcanjo, D. D. R., et al. (2017). Anti-Leishmania Activity of Essential Oil of Myracrodruon urundeuva (Engl.) Fr. All.: Composition, Cytotoxity and Possible Mechanisms of Action. Exp. Parasitol. 175, 59-67. doi:10.1016/j. exppara.2017.02.012

Chávez-Hurtado, P., González-Castañeda, R. E., and Viveros-Paredes, J. M. (2020). $\beta$-Caryophyllene Reduces DNA Oxidation and the Overexpression of Glial Fibrillary Acidic Protein in the Prefrontal Cortex and Hippocampus of D-Galactose-Induced Aged BALB/c Mice. J. Med. Food 23, 515-522. doi:10. 1089/jmf.2019.0111

Cheng, Y., Dong, Z., and Liu, S. (2014). $\beta$-Caryophyllene Ameliorates the Alzheimer-Like Phenotype in APP/PS1 Mice Through CB2 Receptor Activation and the PPAR $\gamma$ Pathway. Pharmacology 94, 1-12. doi:10.1159/ 000362689

Cheng, Y., Wang, Z., Dong, L., Li, J., Yao, Y., Ge, S., et al. (2020). Kidney Disease is Associated With In-Hospital Death of Patients With COVID-19. Kidney Int. 97, 829-838. doi:10.1016/j.kint.2020.03.005

Cho, J. Y., Chang, H.-J., Lee, S.-K., Hwang, J.-K., and Chun, H. S. (2007). Amelioration of Dextran Sulfate Sodium-Induced Colitis in Mice by Oral Administration of $\beta$-caryophyllene, a Sesquiterpene. Life Sci. 80, 932-939. doi:10.1016/j.lfs.2006.11.038

Cho, H.-I., Hong, J.-M., Hwan Kwak, J., Lee, D.-U., Kook Lee, S., Lee, S.-M., et al. (2015). $\beta$-Caryophyllene Alleviates D-Galactosamine and LipopolysaccharideInduced Hepatic Injury Through Suppression of the TLR4 and RAGE Signaling Pathways. Eur. J. Pharmacol. 764, 613-621. doi:10.1016/j.ejphar.2015.08.001

Cho, J. Y., Kim, H. Y., Kim, S.-K., Lee, H. J., and Chun, H. S. (2015). $\beta$-Caryophyllene Attenuates Dextran Sulfate Sodium-Induced Colitis in Mice via Modulation of Gene Expression Associated Mainly with Colon Inflammation. Toxicol. Rep. 2, 1039-1045. doi:10.1016/j.toxrep.2015.07.018
Choi, I. Y., Ju, C., Anthony Jalin, A. M. A., Prather, P. L., and Kim, W.-K. (2013). Activation of Cannabinoid CB2 Receptor-Mediated AMPK/CREB Pathway Reduces Cerebral Ischemic Injury. Am. J. Pathol. 182, 928-939. doi:10.1016/j. ajpath.2012.11.024

Choi, I.-Y., Prather, P. L., and Kim, W.-K. (2013). Activation of Cannabinoid CB2 Receptor-Mediated AMPK/CREB Pathway Reduces Cerebral Ischemic Injury. Am. J. Pathol. 182, 928-939. doi:10.1016/j.ajpath.2012.11.024

Ciavarella, C., Motta, I., and Valente, S. (2020). Pharmacological (Or Synthetic) and Nutritional Agonists of PPAR- $\gamma$ as Candidates for Cytokine Storm Modulation in COVID-19 Disease. Molecules 25, 2076. doi:10.3390/ molecules 25092076

Costantino, C. M., Yewdall, A. W., Devi, L. A., and Chen, B. K. (2012). Cannabinoid Receptor 2-mediated Attenuation of CXCR4-Tropic HIV Infection in Primary CD4+ T Cells. PLOS ONE 7, e33961. doi:10.1371/ journal.pone.0033961

Costiniuk, C. T., and Jenabian, M.-A. (2020). Acute Inflammation and Pathogenesis of SARS-CoV-2 Infection: Cannabidiol as a Potential Antiinflammatory Treatment? Cytokine Growth Factor Rev. 53, 63-65. doi:10. 1016/j.cytogfr.2020.05.008

Csóka, B., Rajesh, M., Federici, S., Deitch, E. A., Bátkai, S., Pacher, P., et al. (2009). CB2 Cannabinoid Receptors Contribute to Bacterial Invasion and Mortality in Polymicrobial Sepsis. PLOS ONE 4, e6409. doi:10.1371/journal. pone.0006409

D'Ascola, A., Irrera, N., Ettari, R., Bitto, A., Pallio, G., Mannino, F., et al. (2019). Exploiting Curcumin Synergy With Natural Products Using Quantitative Analysis of Dose-Effect Relationships in an Experimental In Vitro Model of Osteoarthritis. Front. Pharmacol. 10, 1347. doi:10.3389/fphar.2019.01347

da Silva, J. K. R., Figueiredo, P. L. B., Byler, K. G., and Setzer, W. N. (2020). Essential Oils as Antiviral Agents, Potential of Essential Oils to Treat SARS-CoV-2 Infection: An In-Silico Investigation. IJMS 21, 3426. doi:10.3390/ijms21103426

Dahham, S., Tabana, Y., Iqbal, M., Ezzat, M., Majid, A., Majid, A., et al. (2015). The Anticancer, Antioxidant and Antimicrobial Properties of the Sesquiterpene $\beta$-Caryophyllene From the Essential Oil of Aquilaria crassna. Molecules 20, 11808-11829. doi:10.3390/molecules200711808

D’Amico, F., Baumgart, D. C., Danese, S., and Peyrin-Biroulet, L. (2020). Diarrhea During COVID-19 Infection: Pathogenesis, Epidemiology, Prevention, and Management. Clin. Gastroenterol. Hepatol. 18, 1663-1672. doi:10.1016/j.cgh. 2020.04.001

De, J., Lu, Y., Ling, L., Peng, N., and Zhong, Y. (2017). Essential Oil Composition and Bioactivities of Waldheimia glabra (Asteraceae) from Qinghai-Tibet Plateau. Molecules 22, 460. doi:10.3390/molecules22030460

de Oliveira, M. R. C., da Silva, B. A. F., Oliveira Brito Pereira Bezerra, A., Oliveira Tintino, C. D. M., Afonso Pereira de Oliveira, V., Boligon, A. A., et al. (2019). GC-MS Chemical Characterization and In Vitro Evaluation of Antioxidant and Toxic Effects Using Drosophila melanogaster Model of the Essential Oil of Lantana montevidensis (Spreng) Briq. Medicina 55, 194. doi:10.3390/ medicina55050194

de Pinho, J. P., Silva, A., Pinheiro, B., de Carvalho Bayma, J., Lahlou, S., da Cunha Sousa, P., et al. (2012). Antinociceptive and Antispasmodic Effects of the Essential Oil of Ocimum micranthum: Potential Anti-inflammatory Properties. Planta Med. 78, 681-685. doi:10.1055/s-0031-1298372

Dhama, K., Tiwari, R., Rana, R., Khurana, S. K., Khan, R. U., Alagawany, M., et al. (2018). Medicinal and Therapeutic Potential of Herbs and Plant Metabolites/ Extracts Countering Viral Pathogens - Current Knowledge and Future Prospects. Curr. Drug. Metab. 19, 236-263. doi:10.2174/ 1389200219666180129145252

Dhama, K., Patel, S. K., Tiwari, R., Malik, Y. S., Singh, R., Sah, R., et al. (2020). An Update on SARS-CoV-2/COVID-19 With Particular Reference to its Clinical Pathology, Pathogenesis, Immunopathology and Mitigation Strategies. Trav. Med. Infect. Dis. 37, 101755. doi:10.1016/j.tmaid.2020.101755

Di Giacomo, S., Mazzanti, G., and Di Sotto, A. (2016). Mutagenicity of Cigarette Butt Waste in the Bacterial Reverse Mutation Assay: The Protective Effects of $\beta$-Caryophyllene and $\beta$-Caryophyllene Oxide. Environ. Toxicol. 31, 1319-1328. doi:10.1002/tox.22136

Di Sotto, A., Mazzanti, G., Carbone, F., Hrelia, P., and Maffei, F. (2010). Inhibition by $\beta$-Caryophyllene of Ethyl Methanesulfonate-Induced Clastogenicity in Cultured Human Lymphocytes. Mutat. Res. 699, 23-28. doi:10.1016/j. mrgentox.2010.04.008 
Ding, X., Chen, M., Kang, Y., Lou, J., and Liu, Z. (2020). Dynamic Profile and Clinical Implications of Hematological Parameters in Hospitalized Patients With Coronavirus Disease 2019. Clin. Chem. Lab. Med. 58, 1365-1371. doi:10. 1515/cclm-2020-0411

Diniz, L. R. L., Perez-Castillo, H. A., and de Sousa, D. P. (2021). Bioactive Terpenes and Their Derivatives as Potential SARS-CoV-2 Proteases Inhibitors From Molecular Modeling Studies. Biomolecules 11, 74. doi:10.3390/biom11010074

Dong, X., Cao, Y., Lu, X., Du, H., Yan, Y., Akdis, C. A., et al. (2020). Eleven Faces of Coronavirus Disease 2019. Allergy 75, 1699-1709. doi:10.1111/all.14289

Du, L., Ma, Y., Liu, M., and Tang, H. (2017). Peroxisome Proliferators Activated Receptor (PPAR) Agonists Activate Hepatitis B Virus Replication In Vivo. Virol. J. 14, 96. doi:10.1186/s12985-017-0765-x

Duschatzky, C. B., Possetto, M. L., Talarico, L. B., Michis, F., Almeida, N. V., de Lampasona, M. P., et al. (2005). Evaluation of Chemical and Antiviral Properties of Essential Oils from South American Plants. Antivir. Chem. Chemother. 16, 247-251. doi:10.1177/095632020501600404

Effenberger, M., Nairz, M., Seifert, M., Hilbe, R., Seiwald, S., Scholl-Buergi, S., et al. (2020). Faecal Calprotectin Indicates Intestinal Inflammation in COVID-19. Gut 69, 1543-1544. doi:10.1136/gutjnl-2020-321388

El-Hosseiny, L. S., Alqurashy, N. N., and Sheweita, S. A. (2016). Oxidative Stress Alleviation by Sage Essential Oil in Co-Amoxiclav Induced Hepatotoxicity in Rats. Int. J. Biomed. Sci. 12, 71-78.

El-Sheikh, S. M. A., Abd El-Alim, A. E.-A. F., Galal, A. A. A., El-Sayed, R. G., and El-Naseery, N. I. (2019). Anti-Arthritic Effect of $\beta$-Caryophyllene and its Ameliorative Role on Methotrexate And/or Leflunomide-Induced Side Effects in Arthritic Rats. Life Sci. 233, 116750. doi:10.1016/j.lfs.2019. 116750

Esposito, G., Lu, J., Corpetti, C., and Sarnelli, G. (2020). The Potential of Cannabidiol in the COVID-19 Pandemic. Br. J. Pharmacol. 177, 4967-4970. doi:10.1111/bph.15157

Fanelli, V., Stallone, G., Ronco, C., and Castellano, G. (2020). Acute Kidney Injury in SARS-CoV-2 Infected Patients. Crit. Care 24, 155. doi:10.1186/s13054-02002872-z

Feng, G., Zheng, K. I., Yan, Q.-Q., Targher, G., Byrne, C. D., Poucke, S. V., et al. (2020). COVID-19 and Liver Dysfunction: Current Insights and Emergent Therapeutic Strategies. J. Clin. translational Hepatol. 8, 1-7. doi:10.14218/ JCTH.2020.00018

Fontes, L. B. A., Dias, D., Aarestrup, B. J. V., Da Silva Filho, A. A., and Corrêa, J. (2017). $\beta$-Caryophyllene Ameliorates the Development of Experimental Autoimmune Encephalomyelitis in C57BL/6 Mice. Biomed. Pharmacother. 91, 257-264. doi:10.1016/j.biopha.2017.04.092

Friedman, S. L., Neuschwander-Tetri, B. A., and Rinella, M. (2018). Mechanisms of NAFLD Development and Therapeutic Strategies. Nat. Med. 24, 908-922. doi:10.1038/s41591-018-0104-9

Fukuoka, K., Okuda, H., Kitayama, T., Shirai, M., Komai, K., Komemushi, S., et al. (2004). Inhibitory Actions of Several Natural Products on Proliferation of Rat Vascular Smooth Muscle Cells Induced by Hsp60 from Chlamydia pneumoniae J138. J. Agric. Food Chem. 52, 6326-6329. doi:10.1021/jf0351164

García, C. C., Duschatzky, C., and Damonte, E. B. (2003). Virucidal Activity of Essential Oils From Aromatic Plants of San Luis, Argentina. Phytother. Res. 17, 1073-1075. doi:10.1002/ptr.1305

García, L. F. (2020). Immune Response, Inflammation, and the Clinical Spectrum of COVID-19. Front. Immunol. 11, 1441. doi:10.3389/fimmu.2020.01441

Geddo, F., Querio, G., Maffei, M. E., Bovolin, P., and Gallo, M. P. (2019). PipeNigFL, A Fluid Extract of Black Pepper (Piper Nigrum L.) With a High Standardized Content of Trans- $\beta$-Caryophyllene, Reduces Lipid Accumulation in 3T3-L1 Preadipocytes and Improves Glucose Uptake in C2C12 Myotubes. Nutrients 11, 2788. doi:10.3390/nu11112788

Gertsch, J., Leonti, M., Raduner, S., Chen, J.-Z., Xie, X.-Q., Altmann, K.-H., et al. (2008). Beta-caryophyllene is a Dietary Cannabinoid. Proc. Natl. Acad. Sci. 105, 9099-9104. doi:10.1073/pnas.0803601105

Gertsch, J. (2008). Antiinflammatory Cannabinoids in Diet - Towards a Better Understanding of CB2 Receptor Action? Commun. Integr. Biol. 1, 26-28. doi:10.4161/cib.1.1.6568

Goodridge, H. S., Ahmed, S. S., Curtis, N., Levy, O., Netea, M. G., Pollard, A. J., et al. (2016). Harnessing the Beneficial Heterologous Effects of Vaccination. Nat. Rev. Immunol. 16, 392-400. doi:10.1038/nri.2016.43
Hammad, F. T., Ojha, S., Azimullah, S., and Lubbad, L. (2018). Does $\beta$-Caryophyllene Protect Against Renal Dysfunction Following IschemiaReperfusion Injury in the Rat? Int. J. Physiol. Pathophysiol. Pharmacol. 10, 163-171.

Hammami, S., Faidi, K., Dhaouadi, H., Aouni, M., Aouni, M., and Joshi, R. (2015). Essential Oil Composition, Antioxidant, Cytotoxic and Antiviral Activities of Teucrium pseudochamaepitys Growing Spontaneously in Tunisia. Molecules 20, 20426-20433. doi:10.3390/molecules201119707

Harb, A. A., Bustanji, Y. K., and Abdalla, S. S. (2018). Hypocholesterolemic Effect of $\beta$-Caryophyllene in Rats Fed Cholesterol and Fat Enriched Diet. J. Clin. Biochem. Nutr. 62, 230-237. doi:10.3164/jcbn.17-3

Hassanin, O., Abdallah, F., and Gallal, A. A. (2020). In Vitro and In Vivo Experimental Trials to Assess the Modulatory Influence of $\beta$-Caryophyllene on NDV Replication and Immunopathogenesis. Comp. Immunol. Microbiol. Infect. Dis. 73, 101547. doi:10.1016/j.cimid.2020.101547

He, Q., Zhan, J., and Zhang, Z. (2019). Cannabinoid Receptor 2: A Potential Novel Therapeutic Target for Sepsis? Acta Clin. Belg. 74, 70-74. doi:10.1080/ 17843286.2018.1461754

Hecker, M., Behnk, R. E., Vadász, I., Herold, S., Seeger, W., and Mayer, K. (2015). PPAR-a Activation Reduced LPS-Induced Inflammation in Alveolar Epithelial Cells. Exp. Lung Res. 41, 393-403. doi:10.3109/01902148.2015.1046200

Hensel, A., Kayser, O., Hempel, G., and Kraft, K. (2020). Challenges at the Time of COVID-19: Opportunities and Innovations in Antivirals From Nature. Planta Med. 86, 659-664. doi:10.1055/a-1177-4396

Hernández-Cervantes, R., Méndez-Díaz, M., Prospéro-García, O., and MoralesMontor, J. (2017). Immunoregulatory Role of Cannabinoids During Infectious Disease. Neuroimmunomodulation 24, 183-199. doi:10.1159/000481824

Horváth, B., Mukhopadhyay, P., Kechrid, M., Tanchian, G., Wink, D. A., Gertsch, J., et al. (2012). $\beta$-Caryophyllene Ameliorates Cisplatin-Induced nephrotoxicity in a Cannabinoid 2 Receptor-dependent Manner. Free Radic. Biol. Med. 52, 1325-1333. doi:10.1016/j.freeradbiomed.2012.01.014

Howlett, A. C., and Abood, M. E. (2017). CB 1 and CB 2 Receptor Pharmacology. Adv. Pharmacol. 80, 169-206. doi:10.1016/bs.apha.2017.03.007

Huang, S., Jiang, L., Zhang, R., Peebles, R. S., Mack, M., Kaplan, M. H., et al. (2019). PPAR- $\gamma$ in Macrophages Limits Pulmonary Inflammation and Promotes Host Recovery Following Respiratory Viral Infection. J. Virol. 93, e00019-e00030. doi:10.1128/JVI.00030-19

Huang, C., Wang, Y., Li, X., Ren, L., Zhao, J., Hu, Y., et al. (2020). Clinical Features of Patients Infected With 2019 Novel Coronavirus in Wuhan, China. Lancet 395, 497-506. doi:10.1016/S0140-6736(20)30183-5

Huang, X., Wei, F., and Wen, L. (2020). Epidemiology and Clinical Characteristics of COVID-19. Arch. Iran Med. 23, 268-271. doi:10.34172/aim.2020.09

Hwang, E.-S., and Kim, G. H. (2013). Safety Evaluation of Chrysanthemum indicum L. Flower Oil by Assessing Acute Oral Toxicity, Micronucleus Abnormalities, and Mutagenicity. Prev. Nutr. Food Sci. 18, 111-116. doi:10. 3746/pnf.2013.18.2.111

Hwang, E.-S., Kim, H.-B., Han, G., Han, S.-Y., Lee, E.-A., Yoon, J.-H., et al. (2020). Antidepressant-Like Effects of $\beta$-Caryophyllene on Restraint Plus StressInduced Depression. Behav. Brain Res. 380, 112439. doi:10.1016/j.bbr.2019. 112439

Imai, Y., Kuba, G. G., Perkmann, T., van Loo, G., Ermolaeva, M., Veldhuizen, R., et al. (2008). Identification of Oxidative Stress and Toll-like Receptor 4 Signaling as a Key Pathway of Acute Lung Injury. Cell 133, 235-249. doi:10. 1016/j.cell.2008.02.043

Irrera, N., Mazzon, E., Mannino, F., Squadrito, V., Arcoraci, V., Minutoli, L., et al. (2019). $\beta$-Caryophyllene Mitigates Collagen Antibody Induced Arthritis (CAIA) in Mice Through a Cross-Talk Between CB2 and PPAR- $\gamma$ Receptors. Biomolecules 9, 326. doi:10.3390/biom9080326

Irrera, N., Mannino, F., Arcoraci, V., Rottura, M., Ieni, A., Minutoli, L., et al. (2020). $\beta$-Caryophyllene Inhibits Cell Proliferation through a Direct Modulation of CB2 Receptors in Glioblastoma Cells. Cancers 12, 1038. doi:10.3390/ cancers 12041038

Javed, H., Azimullah, S., and Haque, M. E. (2016). Cannabinoid Type 2 (CB2) Receptors Activation Protects Against Oxidative Stress and Neuroinflammation Associated Dopaminergic Neurodegeneration in Rotenone Model of Parkinson's Disease. Front. Neurosci. 10, 321. doi:10. 3389/fnins.2016.00321 
Jean, S. S., and Hsueh, P.-R. (2020). Old and Re-Purposed Drugs for the Treatment of COVID-19. Expert Rev. Anti-Infect. Ther. 18, 843-847. doi:10.1080/ 14787210.2020 .1771181

Jiménez-Ruiz, A., García-Grimshaw, M., and Ruiz-Sandoval, J. L. (2020). Neurological Manifestations of COVID-19. Gac. Med. Mex. 156, 156. doi:10. 24875/GMM.M20000380

Jin, Y., Chen, S., Zhang, W., and Duan, G. (2020). Virology, Epidemiology, Pathogenesis, and Control of COVID-19. Viruses 12, 372. doi:10.3390/ v12040372

Kamikubo, R., Kai, K., Tsuji-Naito, K., and Akagawa, M. (2016). $\beta$-Caryophyllene Attenuates Palmitate-Induced Lipid Accumulation Through AMPK Signaling by Activating CB2 Receptor in Human HepG2 Hepatocytes. Mol. Nutr. Food Res. 60, 2228-2242. doi:10.1002/mnfr.201600197

Kamyab, A., and Eshraghian, A. (2013). Anti-Inflammatory, Gastrointestinal and Hepatoprotective Effects of Ocimum sanctum Linn: An Ancient Remedy With New Application. Inflamm. Allergy Drug Targets 12, 378-384. doi:10.2174/ 1871528112666131125110017

Kandeel, M., and Al-Nazawi, M. (2020). Virtual Screening and Repurposing of FDA Approved Drugs against COVID-19 Main Protease. Life Sci. 251, 117627. doi:10.1016/j.lfs.2020.117627

Kapellos, T. S., Hussain, M. T., Rainger, G. E., Greaves, D. R., and Iqbal, A. J. (2019). Cannabinoid Receptor 2 Deficiency Exacerbates Inflammation and Neutrophil Recruitment. FASEB J. 33, 6154-6167. doi:10.1096/fj.201802524R

Karmaus, P. W., Chen, W., Kaplan, B. L., and Kaminski, N. E. (2012). $\Delta 9-$ Tetrahydrocannabinol Suppresses Cytotoxic $\mathrm{T}$ Lymphocyte Function Independent of $\mathrm{CB} 1$ and $\mathrm{CB} 2$, Disrupting Early Activation Events. J. Neuroimmune Pharmacol. 7, 843-855. doi:10.1007/s11481-011-9293-4

Keam, S., Megawati, S. K., Dhama, K., and Harapan, H. (2020). Immunopathology and Immunotherapeutic Strategies in Severe Acute Respiratory Syndrome Coronavirus 2 Infection. Rev. Med. Virol. 30, e2123. doi:10.1002/rmv.2123

Kelany, M. E., and Abdallah, M. A. (2016). Protective Effects of Combined $\beta$-Caryophyllene and Silymarin Against Ketoprofen-Induced Hepatotoxicity in Rats. Can. J. Physiol. Pharmacol. 94, 739-744. doi:10.1139/cjpp-2015-0607

Khodadadi, H., Salles, É. L., Costigliola, V., Yu, J. C., Vaibhav, K., Hess, D. C., et al. (2020). Cannabidiol Modulates Cytokine Storm in Acute Respiratory Distress Syndrome Induced by Simulated Viral Infection Using Synthetic RNA. Cannabis Cannabinoid Res. 5, 197-201. doi:10.1089/can.2020.0043

Khomich, O., Kochetkov, S., Bartosch, B., and Ivanov, A. V. (2018). Redox Biology of Respiratory Viral Infections. Viruses 10, 392. doi:10.3390/v10080392

Kim, D. W., Seo, K. H., Oh, J.-W., Cho, J. K., Lee, K. H., and Park, K. H. (2014). Phenolic Phytochemical Displaying SARS-CoV Papain-Like Protease Inhibition From the Seeds of Psoralea corylifolia. J. Enzyme Inhib. Med. Chem. 29, 59-63. doi:10.3109/14756366.2012.753591

Klauke, A.-L., Zimmer, A. M., Gertsch, J., and Zimmer, A. (2014). The Cannabinoid CB2 Receptor-Selective Phytocannabinoid Beta-Caryophyllene Exerts Analgesic Effects in Mouse Models of Inflammatory and Neuropathic Pain. Eur. Neuropsychopharmacol. 24, 608-620. doi:10.1016/j.euroneuro.2013. 10.008

Koubaa, F. G., Abdennabi, R., and Salah, A. S. B. (2019). Microwave Extraction of Salvia officinalis Essential Oil and Assessment of its GC-MS Identification and Protective Effects Versus Vanadium-Induced Nephrotoxicity in Wistar Rats Models. Arch. Physiol. Biochem. 125, 404-413. doi:10.1080/13813455.2018. 1478427

Koyama, S., Novotny, M. V., Davis, K., Kao, C. C., Matsunami, H., and Mescher, A. (2019). Beta-Caryophyllene Enhances Wound Healing Through Multiple Routes. PLOS ONE 14, e0216104. doi:10.1371/journal.pone.0216104

Ku, C.-M., and Lin, J.-Y. (2013). Anti-inflammatory Effects of 27 Selected Terpenoid Compounds Tested Through Modulating Th1/Th2 Cytokine Secretion Profiles Using Murine Primary Splenocytes. Food Chem. 141, 1104-1113. doi:10.1016/j.foodchem.2013.04.044

Lai, C.-C., Ko, W.-C., Lee, P.-I., and Hsueh, P.-R. (2020). Extra-Respiratory Manifestations of COVID-19. Int. J. Antimicrob. Agents 56, 106024. doi:10. 1016/j.ijantimicag.2020.106024

Lai, C.-C., Wang, C.-Y., and Hsueh, P.-R. (2020). Co-Infections Among Patients With COVID-19: The Need for Combination Therapy With non-anti-SARSCoV-2 Agents? J. Microbiol. Immunol. Infect. 53, 505-512. doi:10.1016/j.jmii. 2020.05.013
Lee, I.-C., Huo, T.-I., and Huang, Y.-H. (2020). Gastrointestinal and Liver Manifestations in Patients With COVID-19. J. Chin. Med. Assoc. 83, 521-523. doi:10.1097/JCMA.0000000000000319

Li, H., Wang, D., Chen, Y., and Yang, M. (2020). $\beta$-Caryophyllene Inhibits High Glucose-Induced Oxidative Stress, Inflammation and Extracellular Matrix Accumulation in Mesangial Cells. Int. Immunopharmacol. 84, 106556. doi:10.1016/j.intimp.2020.106556

Lindsey, L. P., Abney, S. E., Uchakina, O. N., Khusial, R. D., Akil, A., and Murnane, K. S. (2019). The Cannabinoid Receptor 2 Agonist, $\beta$-Caryophyllene, Improves Working Memory and Reduces Circulating Levels of Specific Proinflammatory Cytokines in Aged Male Mice. Behav. Brain Res. 372, 112012. doi:10.1016/j.bbr. 2019.112012

Liu, M. W., Su, M., Wang, Y., Qin, L., Liu, X., Tian, M., et al. (2014). Effect of Melilotus Extract on Lung Injury by Upregulating the Expression of Cannabinoid CB2 Receptors in Septic Rats. BMC Complement. Altern. Med. 14, 94. doi:10.1186/1472-6882-14-94

Liu, A. P., Yuan, Q. H., He, Q. W., Chen, K., Liu, Q. S., Li, Z., et al. (2020). Cannabinoid Receptor 2 Activation Alleviates Septic Lung Injury by Promoting Autophagy via Inhibition of Inflammatory Mediator Release. Cell Signal. 69, 109556. doi:10.1016/j.cellsig.2020.109556

Loizzo, M. R., Lampronti, I., Menichini, F., Gambari, R., Cinatl, J., and Doerr, H. W. (2008). Phytochemical Analysis and In Vitro Evaluation of the Biological Activity Against Herpes Simplex Virus Type 1 (HSV-1) of Cedrus libani A. Rich. Phytomedicine 15, 79-83. doi:10.1016/j.phymed.2007.03.013

Lorençoni, M. F., Figueira, M. M., Endringer, D. C., Scherer, R., Barth, T., Vilela Bertolucci, S. K., et al. (2020). Chemical Composition and Anti-inflammatory Activity of Essential Oil and Ethanolic Extract of Campomanesia phaea (O. Berg.) Landrum Leaves. J. Ethnopharmacol. 252, 112562. doi:10.1016/j.jep.2020. 112562

Lou, J., Cao, G., Li, R., Liu, J., Dong, Z., and Xu, L. (2016). $\beta$-Caryophyllene Attenuates Focal Cerebral Ischemia-Reperfusion Injury by Nrf2/HO-1 Pathway in Rats. Neurochem. Res. 41, 1291-1304. doi:10.1007/s11064-016-1826-Z

Lou, J., Teng, Z., Zhang, L., Ma, L., Wang, F., Tian, X., et al. (2017). $\beta$-Caryophyllene/Hydroxypropyl- $\beta$-Cyclodextrin Inclusion Complex Improves Cognitive Deficits in Rats With Vascular Dementia Through the Cannabinoid Receptor Type 2 -Mediated Pathway. Front. Pharmacol. 8, 2. doi:10.3389/fphar.2017.00002

Mahmoud, M. F., El Swefy, S., Hasan, R. B., and Ibrahim, A. (2014). Role of Cannabinoid Receptors in Hepatic Fibrosis and Apoptosis Associated With Bile Duct Ligation in Rats. Eur. J. Pharmacol. 742, 118-124. doi:10.1016/j.ejphar. 2014.08.021

Mahmoud, M. F., Swefy, S. E., and Hasan, R. A. (2014). Role of Cannabinoid Receptors in Hepatic Fibrosis and Apoptosis Associated With Bile Duct Ligation in Rats. Eur. J. Pharmacol. 742, 118-124. doi:10.1016/j.ejphar.2014. 08.021

Mahmud, S., Uddin, M. A. R., Rahman, M. E., Shehab, M. N., Islam, A., Alom, M. W., et al. (2020). Molecular Docking and Dynamics Study of natural Compound for Potential Inhibition of Main Protease of SARS-CoV-2. J. Biomol. Struct. Dyn. 2020, 1-9. doi:10.1080/07391102.2020.1796808

Manzo, A., Dallavalle, S., Catalano, E., Scarì, G., and Giorgi, A. (2016). Screening of the Chemical Composition and Bioactivity of Waldheimia glabra (Decne.) Regel Essential Oil. J. Sci. Food Agric. 96, 3195-3201. doi:10.1002/jsfa.7499

McCord, J. M., Hybertson, B. M., and Gao, B. (2020). Nrf2 Activator PB125 as a Potential Therapeutic Agent against COVID-19. Antioxidants 9, 518. doi:10. 3390/antiox9060518

Meeran, M. F. N., Adeghate, E., and Ojha, S. (2019). $\beta$-Caryophyllene, A Natural Bicyclic Sesquiterpene Attenuates Doxorubicin-Induced Chronic Cardiotoxicity via Activation of Myocardial Cannabinoid Type-2 (CB2) Receptors in Rats. Chem.-Biol. Interact. 304, 158-167. doi:10.1016/j.cbi.2019. 02.028

Meng, X., Li, D., Zhou, D., Liu, Q., and Fan, S. (2016). Chemical Composition, Antibacterial Activity and Related Mechanism of the Essential Oil From the Leaves of Juniperus rigida Sieb. et Zucc Against Klebsiella pneumoniae. J. Ethnopharmacol. 194, 698-705. doi:10.1016/j.jep.2016.10.050

Meza, A., and Lehmann, C. (2018). Betacaryophyllene - A Phytocannabinoid as Potential Therapeutic Modality for Human Sepsis? Med. Hypotheses 110, 68-70. doi:10.1016/j.mehy.2017.10.025 
Mira, J. C., Gentile, L. F., Brakenridge, S. C., Mohr, A. M., Moore, F. A., and Moldawer, L. L. (2017). Sepsis Pathophysiology, Chronic Critical Illness, and Persistent Inflammation-Immunosuppression and Catabolism Syndrome. Crit. Care Med. 45, 253-262. doi:10.1097/CCM.0000000000002074

Mohamed, W. A., Abd-Elhakim, Y. M., and Farouk, S. M. (2016). Protective Effects of Ethanolic Extract of Rosemary Against Lead-Induced Hepato-Renal Damage in Rabbits. Exp. Toxicol. Pathol. 68, 451-461. doi:10.1016/j.etp.2016.07.003

Mohamed, K., Sharifudin, S. M., and Duduku, K. (2018). NiO nanoparticles Induce Cytotoxicity Mediated through ROS Generation and Impairing the Antioxidant Defense in the Human Lung Epithelial Cells (A549): Preventive Effect of Pistacia lentiscus Essential Oil. Toxicol. Rep. 5, 480-488. doi:10.1016/j. toxrep.2018.03.012

Mohammed, A., Singh, N., Cai, G., Putluri, N., Nagarkatti, P., and Nagarkatti, M. (2020). $\Delta$ 9-Tetrahydrocannabinol Prevents Mortality From Acute Respiratory Distress Syndrome Through the Induction of Apoptosis in Immune Cells, Leading to Cytokine Storm Suppression. IJMS 21, 6244. doi:10.3390/ ijms21176244

Mondal, P., Natesh, J., Salam, A., and Meeran, S. M. (2020). Traditional Medicinal Plants Against Replication, Maturation and Transmission Targets of SARSCoV-2: Computational Investigation. J. Biomol. Struct. Dyn., 1-18. doi:10.1080/ 07391102.2020 .1842246

Moussaoui, N. E., Sanchez, G., and Khay, E. O. (2013). Antibacterial and Antiviral Activities of Essential Oils of Northern Moroccan Plants. Biotechnol. J. Int. 3 (3a), 318-331. doi:10.9734/BBJ/2013/3596

Munro, S., Thomas, K. L., and Abu-S, M. (1993). Molecular Characterization of a Peripheral Receptor for Cannabinoids. Nature 365, 61-65. doi:10.1038/ 365061a0

Muthuramalingam, P., Karthika, C., Gowrishankar, S., Pandian, S. K., Ramesh, M., and Chen, J.-T. (2020). Global Multi-Omics and Systems Pharmacological Strategy Unravel the Multi-Targeted Therapeutic Potential of Natural Bioactive Molecules Against COVID-19: An In Silico Approach. Genomics 112, 4486-4504. doi:10.1016/j.ygeno.2020.08.003

Nagarkatti, P., Miranda, K., and Nagarkatti, M. (2020). Use of Cannabinoids to Treat Acute Respiratory Distress Syndrome and Cytokine Storm Associated With Coronavirus Disease-2019. Front. Pharmacol. 11, 589438. doi:10.3389/ fphar.2020.589438

Nagoor Meeran, M. F., Sharma, C., and Ojha, S. (2020). CB2 Receptor-Selective Agonists as Candidates for Targeting Infection, Inflammation, and Immunity in SARS-CoV -2 Infections. Drug Dev. Res. 82, 7-11. doi:10. $1002 / d d r .21752$

Narkhede, R. R., Pise, A. V., and Cheke, R. S. (2020). Recognition of Natural Products as Potential Inhibitors of COVID-19 Main Protease (Mpro): In-Silico Evidences. Nat. Prod. Bioprospect. 10, 297-306. doi:10.1007/s13659-02000253-1

Nasi, A., Melief, C., Rockberg, J., Arens, R., Kouretas, D., Sjölin, J., et al. (2020). Reactive Oxygen Species as an Initiator of Toxic Innate Immune Responses in Retort to SARS-CoV-2 in an Ageing Population, Consider N-Acetylcysteine as Early Therapeutic Intervention. Toxicol. Rep. 7, 768-771. doi:10.1016/j.toxrep. 2020.06.003

Ng, Y. C., Kim, Y. W., Lee, J.-S., and Jung Song, M. (2018). Antiviral Activity of Schizonepeta tenuifolia Briquet Against Noroviruses via Induction of Antiviral Interferons. J. Microbiol. 56, 683-689. doi:10.1007/s12275-018-8228-7

Nieto-Bobadilla, M. S., Tesse, N., Willart, J.-F., Dubreuil, L., Siepmann, J., and Neut, C. (2015). Controlled Delivery of a New Broad Spectrum Antibacterial Agent Against Colitis: In Vitro and In Vivo Performance. Eur. J. Pharmaceutics Biopharmaceutics 96, 152-161. doi:10.1016/j.ejpb.2015.07.012

Nuzzo, D., and Picone, P. (2020). Potential Neurological Effects of Severe COVID19 Infection. Neurosci. Res. 158, 1-5. doi:10.1016/j.neures.2020.06.009

Oboh, G., Olasehinde, T. A., and Ademosun, A. O. (2014). Essential Oil From Lemon Peels Inhibit Key Enzymes Linked to Neurodegenerative Conditions and Pro-Oxidant Induced Lipid Peroxidation. J. Oleo Sci. 63, 373-381. doi:10. 5650/jos.ess 13166

Ojha, S., Javed, H., and Azimullah, S. (2016). $\beta$-Caryophyllene, a Phytocannabinoid Attenuates Oxidative Stress, neuroinflammation, Glial Activation, and Salvages Dopaminergic Neurons in a Rat Model of Parkinson Disease. Mol. Cell. Biochem 418, 59-70. doi:10.1007/s11010-016-2733-y

Okoh, S. O., Okoh, O. O., and Okoh, A. I. (2019). Inhibitory Effects of Azadirachta indica Secondary Metabolites Formulated Cosmetics on Some Infectious
Pathogens and Oxidative Stress Radicals. BMC Complement. Altern. Med. 19, 123. doi:10.1186/s12906-019-2538-0

Oláh, A., Szekanecz, Z., and Bíró, T. (2017). Targeting Cannabinoid Signaling in the Immune System: "High"-Ly Exciting Questions, Possibilities, and Challenges. Front. Immunol. 8, 1487. doi:10.3389/fimmu.2017.01487

Oliveira-Tintino, C. D. M., Pessoa, R. T., Fernandes, M. N. M., da Silva, B. A. F., de Oliveira, M. R. C., Tintino, S. R., et al. (2018). Anti-inflammatory and Antiedematogenic Action of the Croton campestris A. St.-Hil (Euphorbiaceae) Essential Oil and the Compound $\beta$-Caryophyllene in In Vivo Models. Phytomedicine 41, 82-95. doi:10.1016/j.phymed.2018.02.004

O'Sullivan, S. E. (2016). An Update on PPAR Activation by Cannabinoids. $\mathrm{Br}$. J. Pharmacol. 173, 1899-1910. doi:10.1111/bph.13497

Pandey, A., Khan, M. K., Hamurcu, M., and Gezgin, S. (2020). Natural Plant Products: A Less Focused Aspect for the COVID-19 Viral Outbreak. Front. Plant Sci. 11, 568890. doi:10.3389/fpls.2020.568890

Panfoli, I. (2020). Potential Role of Endothelial Cell Surface Ectopic Redox Complexes in COVID-19 Disease Pathogenesis. Clin. Med. 20, e146-e147. doi:10.7861/clinmed.2020-0252

Pant, A., Akhoon, B. A., and Pandey, R. (2014). Beta-Caryophyllene Modulates Expression of Stress Response Genes and Mediates Longevity in Caenorhabditis elegans. Exp. Gerontol. 57, 81-95. doi:10.1016/j.exger.2014.05.007

Pant, P., Maggi, F., Gyawali, R., and Dall'Acqua, S. (2019). Sesquiterpene Rich Essential Oil From Nepalese bael Tree (Aegle Marmelos (L.) Correa) as Potential Antiproliferative Agent. Fitoterapia 138, 104266. doi:10.1016/j. fitote.2019.104266

Parisotto-Peterle, J., Falkembach, M. C., da Silva Marques, M., Horn, A. P., dos Santos, M. K., da Veiga, V. F., et al. (2020). Healing Activity of Hydrogel Containing nanoemulsified $\beta$-Caryophyllene. Eur. J. Pharm. Sci. 148, 105318. doi:10.1016/j.ejps.2020.105318

Park, J.-Y., Yuk, H. J., Ryu, H. W., Kim, K. S., Park, K. H., Ryu, Y. B., et al. (2017). Evaluation of Polyphenols from Broussonetia papyrifera as Coronavirus Protease Inhibitors. J. Enzyme Inhib. Med. Chem. 32, 504-512. doi:10.1080/ 14756366.2016.1265519

Pastor, F. P., Isorna Folgar, M., Carvalho, N., Carvalho, F., Horcajadas, F. A., et al. (2020). Therapeutic Cannabis and COVID-19: Between Opportunism and Infoxication. Adicciones 32, 167-172. doi:10.20882/adicciones.1603

Patra, K. C., Singh, B., and Pareta, S. (2010). A Validated HPTLC Method for Determination Oftrans-Caryophyllene from Polyherbal Formulations. Nat. Prod. Res. 24, 1933-1938. doi:10.1080/14786419.2010.497147

Patra, T., Sasaki, R., Meyer, K., Ray, R. B., and Ray, R. (2019). Transforming Growth Factor $\beta$ Acts as a Regulatory Molecule for Lipogenic Pathways Among Hepatitis C Virus Genotype-Specific Infections. J. Virol. 93, e00811-e00819. doi:10.1128/JVI.00811-19

Picciolo, G., Oteri, G., Irrera, N., and Squadrito, F. (2020). $\beta$-Caryophyllene Reduces the Inflammatory Phenotype of Periodontal Cells by Targeting CB2 Receptors. Biomedicines 8, 164. doi:10.3390/biomedicines8060164

Pinho-da-Silva, L., de Morais, S. M., Coelho-de-Souza, A. N., Lahlou, S., and LealCardoso, J. H. (2010). Croton sonderianus Essential Oil Samples Distinctly Affect Rat Airway Smooth Muscle. Phytomedicine 17, 721-725. doi:10.1016/j. phymed.2010.01.015

Pinho-da-Silva, L., Ceccatto, V. M., Coelho-de-Souza, A. N., Santos Cruz, J., and Leal-Cardoso, J. H. (2012). Trans-Caryophyllene, A Natural Sesquiterpene, Causes Tracheal Smooth Muscle Relaxation through Blockade of Voltagedependent Ca2+ Channels. Molecules 17, 11965-11977. doi:10.3390/ molecules171011965

Poddighe, L., Boi, M., Lisai, S., Murru, E., Muredda, L., Collu, M., et al. (2018). Acute Administration of Beta-Caryophyllene Prevents Endocannabinoid System Activation during Transient Common Carotid Artery Occlusion and Reperfusion. Lipids Health Dis. 17, 23. doi:10.1186/s12944-018-0661-4

Potus, F., Breton-Gagnon, E., Lajoie, A. C., Boucherat, O., Bonnet, S., and Provencher, S. (2020). Novel Insights on the Pulmonary Vascular Consequences of COVID-19. Am. J. Physiol. Lung Cell Mol. Physiol. 319, L277-L288. doi:10.1152/ajplung.00195.2020

Prins, G. H., and Olinga, P. (2020). Potential Implications of COVID-19 in NonAlcoholic Fatty Liver Disease. Liver Int. 40, 2568. doi:10.1111/liv.14484

Rabaan, A. A., Yatoo, M. I., Patel, S. K., Pathak, M., Malik, Y. S., Dhama, K., et al. (2020). SARS-CoV-2/COVID-19 and Advances in Developing Potential 
Therapeutics and Vaccines to Counter This Emerging Pandemic. Ann. Clin. Microbiol. Antimicrob. 19, 40. doi:10.1186/s12941-020-00384-w

Raj, V., Park, J. G., Kim, T., Ham, J., and Lee, J. (2021). Assessment of Antiviral Potencies of Cannabinoids Against SARS-CoV-2 Using Computational and In Vitro Approaches. Int. J. Biol. Macromol. 168, 474-485. doi:10.1016/j.ijbiomac. 2020.12.020

Rajesh, M., Liaudet, L., Huffman, J. W., Csiszar, A., Ungvari, Z., Mackie, K., et al. (2007). CB2-Receptor Stimulation Attenuates TNF- $\alpha$-Induced Human Endothelial Cell Activation, Transendothelial Migration of Monocytes, and Monocyte-Endothelial Adhesion. Am. J. Physiol.Heart Circulat. Physiol. 293, H2210-H2218. doi:10.1152/ajpheart.00688.2007

Rajesh, M., Mackie, K., and Pacher, P. (2008). CB2 Cannabinoid Receptor Agonists Attenuate TNF- $\alpha$-Induced Human Vascular Smooth Muscle Cell Proliferation and Migration. Br. J. Pharmacol. 153, 347-357. doi:10.1038/sj.bjp.0707569

Ramirez, S. H., Reichenbach, N. L., Merkel, S. F., Wang, X., Ho, W.-Z., and Persidsky, Y. (2013). Attenuation of HIV-1 Replication in Macrophages by Cannabinoid Receptor 2 Agonists. J. Leukoc. Biol. 93, 801-810. doi:10.1189/jlb. 1012523

Rather, M. A., Dar, B. A., Dar, M. Y., Shah, W. A., Bhat, B. A., Ganai, B. A., et al. (2012). Chemical Composition, Antioxidant and Antibacterial Activities of the Leaf Essential Oil of Juglans regia L. and its Constituents. Phytomedicine 19, 1185-1190. doi:10.1016/j.phymed.2012.07.018

Rieder, S. A., Chauhan, A., Singh, U., and Nagarkatti, P. (2010). Cannabinoid-induced Apoptosis in Immune Cells as a Pathway to Immunosuppression. Immunobiology 215, 598-605. doi:10.1016/j. imbio.2009.04.001

Rosales-Mendoza, S., Márquez-Escobar, V. A., and Arévalo-Villalobos, J. I. (2020). What Does Plant-Based Vaccine Technology Offer to the Fight against COVID-19? Vaccines 8, 183. doi:10.3390/vaccines 8020183

Rufino, A. T., Salgueiro, L., Cavaleiro, C., and Mendes, A. F. (2015). Evaluation of the Anti-inflammatory, Anti-catabolic and Pro-anabolic Effects of E-Caryophyllene, Myrcene and Limonene in a Cell Model of Osteoarthritis. Eur. J. Pharmacol. 750, 141-150. doi:10.1016/j.ejphar.2015.01.018

Russo, E. B. (2011). Taming THC: Potential Cannabis Synergy and Phytocannabinoid-Terpenoid Entourage Effects. Br. J. Pharmacol. 163, 1344-1364. doi:10.1111/j.1476-5381.2011.01238.x

Sadeghi, H., Sadati, I., Abbaszadeh-Goudarzi, K., Asfaram, A., and Doustimotlagh, A. H. (2020). Antioxidant and Protective Effect of Stachys pilifera Benth Against Nephrotoxicity Induced by Cisplatin in Rats. J. Food Biochem. 44. doi:10.1111/ jfbc. 13190

Saidi, M., Ghafourian, S., Zarin-Abaadi, M., Movahedi, K., and Sadeghifard, N. (2012). In Vitro Antimicrobial and Antioxidant Activity of Black Thyme (Thymbra spicata L.) Essential Oils. Roum. Arch. Microbiol. Immunol. 71, 61-69.

Saldanha, A. A., Santos, H. B., Silva, D. B., Carollo, C. A., Oliveira, F. M., Lopes, D., et al. (2019). Chemical Composition and Evaluation of the Antiinflammatory and Antinociceptive Activities of Duguetia furfuracea Essential Oil: Effect on Edema, Leukocyte Recruitment, Tumor necrosis Factor Alpha Production, iNOS Expression, and Adenosinergic and Opioidergic Systems. J. Ethnopharmacol. 231, 325-336. doi:10.1016/j.jep. 2018.11.017

Saleh, J., Peyssonnaux, C., and Singh, K. K. (2020). Mitochondria and Microbiota Dysfunction in COVID-19 Pathogenesis. Mitochondrion 54, 1-7. doi:10.1016/j. mito.2020.06.008

Salles, É. L., Paffaro, V. A., Costigliola, V., Yu, J. C., Hess, D. C., Dhandapani, K. M., et al. (2020). Cannabidiol (CBD) Modulation of Apelin in Acute Respiratory Distress Syndrome. J. Cell. Mol. Med. 24, 12869-12872. doi:10.1111/jcmm. 15883

Santos, P. S., Oliveira, T. C., Júnior, L. M. R., Figueiras, A., and Nunes, L. C. C. (2018). $\quad \beta$-Caryophyllene Delivery Systems: Enhancing the Oral Pharmacokinetic and Stability. Curr. Pharm. Des. 24, 3440-3453. doi:10. 2174/1381612824666180912151412

Sardinha, J., Kelly, M. E. M., Zhou, J., and Lehmann, C. (2014). Experimental Cannabinoid 2 Receptor-Mediated Immune Modulation in Sepsis. Mediators Inflamm. 2014, 1-7. doi:10.1155/2014/978678

Scavone, C., Rafaniello, C., Zoccoli, A., Berrino, L., Racagni, G., Rossi, F., et al. (2020). Current Pharmacological Treatments for COVID-19: What's next? Br. J. Pharmacol. 177, 4813-4824. doi:10.1111/bph.15072
Schmidt, E., Bail, S., Friedl, S. M., and Jirovetz, L. (2010). Antimicrobial Activities of Single Aroma Compounds. Nat. Prod. Commun. 5, 1365-1368. doi:10.1177/ $1934578 \times 1000500906$

Schnitzler, P., Koch, C., and Reichling, J. (2007). Susceptibility of Drug-Resistant Clinical Herpes Simplex Virus Type 1 Strains to Essential Oils of Ginger, Thyme, Hyssop, and Sandalwood. AAC 51, 1859-1862. doi:10.1128/AAC. 00426-06

Segat, G. C., Manjavachi, M. N., Matias, D. O., Freitas, C. S., Costa, R., and Calixto, J. B. (2017). Antiallodynic Effect of $\beta$-Caryophyllene on Paclitaxel-Induced Peripheral neuropathy in Mice. Neuropharmacology 125, 207-219. doi:10.1016/ j.neuropharm.2017.07.015

Semprini, R., Martorana, A., Ragonese, M., and Motta, C. (2018). Observational Clinical and Nerve Conduction Study on Effects of a Nutraceutical Combination on Painful Diabetic Distal Symmetric Sensory-Motor Neuropathy in Patients With Diabetes Type 1 and Type 2. Minerva Med. 109, 358-362. doi:10.23736/S0026-4806.18.05710-5

Setzer, W. N. (2016). Essential Oils as Complementary and Alternative Medicines for the Treatment of Influenza. Am. J. Essent. Oils Nat. Prod. 4 (4), 16-22.

Sexton, M. (2020). Cannabis in the Time of Coronavirus Disease 2019: The Yin and Yang of the Endocannabinoid System in Immunocompetence. J. Altern. Complement. Med. 26, 444-448. doi:10.1089/acm.2020.0144

Shan, J., Chen, L., and Lu, K. (2017). Protective Effects of Trans-Caryophyllene on Maintaining Osteoblast Function. IUBMB Life 69, 22-29. doi:10.1002/iub. 1584

Sharma, C., Al Kaabi, J. M., Nurulain, S., Amjad Kamal, M., and Ojha, S. (2016). Polypharmacological Properties and Therapeutic Potential of $\beta$-Caryophyllene: A Dietary Phytocannabinoid of Pharmaceutical Promise. CPD 22, 3237-3264. doi:10.2174/1381612822666160311115226

Shayeganmehr, A., Marandi, M. V., Karimi, V., Barinau, A., and Ghalyanchilangeroudi, A. (2018). Zataria multiflora Essential Oil Reduces Replication Rate of Avian Influenza Virus (H9N2 Subtype) in Challenged Broiler Chicks. Br. Poult. Sci. 59, 389-395. doi:10.1080/00071668.2018.1478064

Shim, H. I., Park, Y. S., Kim, N., and Lee, D. H. (2019). Inhibitory Effects of $\beta$-Caryophyllene on Helicobacter pylori Infection: A Randomized DoubleBlind, Placebo-Controlled Study. Korean J. Gastroenterol. 74, 199. doi:10. 4166/kjg.2019.74.4.199

Singh, T. U., Kumar, D., and Singh, R. K. (2020). Drug Repurposing Approach to Fight COVID-19. Pharmacol. Rep. 72, 1479-1508. doi:10.1007/s43440-02000155-6

Sirichaiwetchakoon, K., Lowe, G. M., Kupittayanant, S., and Eumkeb, G. (2020). Pluchea indica (L.) Less. Tea Ameliorates Hyperglycemia, Dyslipidemia, and Obesity in High Fat Diet-Fed Mice. Evidence-Based Complement. Altern. Med. 2020, 1-12. doi:10.1155/2020/8746137

Skolnik, P. R., Rabbi, M. F., Mathys, J.-M., and Greenberg, A. S. (2002). Stimulation of Peroxisome Proliferator-Activated Receptors $\alpha$ and $\gamma$ Blocks HIV-1 Replication and TNFa Production in Acutely Infected Primary Blood Cells, Chronically Infected U1 Cells, and Alveolar Macrophages From HIV-Infected Subjects. J. Acquir. Immune Defic. Syndr. 31, 1-10. doi:10.1097/00126334200209010-00001

Soleimani, M. (2020). Acute Kidney Injury in SARS-CoV-2 Infection: Direct Effect of Virus on Kidney Proximal Tubule Cells. IJMS 21, 3275. doi:10.3390/ ijms 21093275

Srivastava, S., Pant, A., Trivedi, S., and Pandey, R. (2016). Curcumin and $\beta$-caryophellene Attenuate Cadmium Quantum Dots Induced Oxidative Stress and Lethality in Caenorhabditis elegans Model System. Environ. Toxicol. Pharmacol. 42, 55-62. doi:10.1016/j.etap.2016.01.001

Staiano, R. I., Piscitelli, F., Orlando, P., Secondo, A., Granata, F., Lepore, M. T., et al. (2016). Human Lung-Resident Macrophages Express CB1 and CB2 Receptors Whose Activation Inhibits the Release of Angiogenic and Lymphangiogenic Factors. J. Leukoc. Biol. 99, 531-540. doi:10.1189/jlb.3HI1214-584R

Sun, J., Aghemo, A., Forner, A., and Valenti, L. (2020). COVID-19 and Liver Disease. Liver Int. 40, 1278-1281. doi:10.1111/liv.14470

Sweid, A., Tjoumakaris, S. I., Gooch, M. R., Herial, N. A., Zarzour, H., Romo, V., et al. (2020). Cerebral Ischemic and Hemorrhagic Complications of Coronavirus Disease 2019. Int. J. Stroke 15, 733-742. doi:10.1177/ 1747493020937189

Tahamtan, A., NayeriSamieipoor, F. S., Izadi, A., Rashidi-Nezhad, A., and Tavakoli-Yaraki, M. (2018). Effects of Cannabinoid Receptor Type 2 in 
Respiratory Syncytial Virus Infection in Human Subjects and Mice. Virulence 9, 217-230. doi:10.1080/21505594.2017.1389369

Tambe, Y., Tsujiuchi, H., Honda, G., Ikeshiro, Y., and Tanaka, S. (1996). Gastric Cytoprotection of the Non-Steroidal Anti-Inflammatory Sesquiterpene, $\beta$-Caryophyllene. Planta Med. 62, 469-470. doi:10.1055/s-2006-957942

Tang, Y., Liu, J., Zhang, D., Xu, Z., Ji, J., and Wen, C. (2020). Cytokine Storm in COVID-19: The Current Evidence and Treatment Strategies. Front. Immunol. 11, 1708. doi:10.3389/fimmu.2020.01708

Tarumi, W., and Shinohara, K. (2020). Olfactory Exposure to $\beta$-Caryophyllene Increases Testosterone Levels in Women's Saliva. Sex. Med. 8, 525-531. doi:10. 1016/j.esxm.2020.06.001

Tesch, N. R., Mora, F., and Rojas, L. (2011). Chemical Composition and Antibacterial Activity of the Essential Oil of Lantana camara Var. Moritziana. Nat. Prod. Commun. 6, 1031-1034. doi:10.1177/ $1934578 \times 1100600727$

Tian, X., Peng, J., Zhong, J., Pang, J., Lou, J., Li, M., et al. (2016). $\beta$-Caryophyllene Protectsin Vitroneurovascular Unit against Oxygen-Glucose Deprivation and Re-oxygenation-induced Injury. J. Neurochem. 139, 757-768. doi:10.1111/jnc. 13833

Tian, X., Liu, H., Xiang, F., Xu, L., and Dong, Z. (2019). $\beta$-Caryophyllene Protects against Ischemic Stroke by Promoting Polarization of Microglia toward M2 Phenotype via the TLR4 Pathway. Life Sci. 237, 116915. doi:10.1016/j.lfs.2019. 116915

Toguri, J. T., Kelly, M. E. M., and Lehmann, C. (2015). Cannabinoid 2 Receptor Activation Reduces Leukocyte Adhesion and Improves Capillary Perfusion in the Iridial Microvasculature during Systemic Inflammation. CH 61, 237-249. doi:10.3233/CH-151996

Tung, Y.-T., Chua, M. T., Wang, S.-Y., and Chang, S-T. (2008). Anti-inflammation Activities of Essential Oil and Its Constituents From Indigenous cinnamon (Cinnamomum osmophloeum) Twigs. Bioresour. Technol. 99, 3908-3913. doi:10.1016/j.biortech.2007.07.050

ul Qamar, M. T., Alqahtani, S. M., and Alamri, M. A. (2020). Structural Basis of SARS-CoV-2 3CL Pro and Anti-COVID-19 Drug Discovery from Medicinal Plants. J. Pharm. Anal. 10, 313-319. doi:10.1016/j.jpha.2020.03.009

Urasaki, Y., Hill, D. K., and Le, T. T. (2020). Fast-Acting and Receptor-Mediated Regulation of Neuronal Signaling Pathways by Copaiba Essential Oil. IJMS 21, 2259. doi:10.3390/ijms21072259

Varga, Z. V., Matyas, C., Erdelyi, K., Nieri, D., Chicca, A., Nemeth, B. T., et al. (2018). $\quad \beta$-Caryophyllene Protects Against Alcoholic Steatohepatitis by Attenuating Inflammation and Metabolic Dysregulation in Mice. $\mathrm{Br}$. J. Pharmacol. 175, 320-334. doi:10.1111/bph.13722

Venturi, C. R., Montanha, J. A., Bordignon, S. A. L., Roehe, P. M., Fuentefria, A. M., and Henriques, A. T. (2015). Chemical Analysis and In Vitro Antiviral and Antifungal Activities of Essential Oils From Glechon spathulata and Glechon marifolia. Pharm. Biol. 53, 682-688. doi:10.3109/13880209.2014. 936944

Vinciguerra, M., Romiti, S., Fattouch, K., De Bellis, A., and Greco, E. (2020). Atherosclerosis as Pathogenetic Substrate for Sars-Cov2 Cytokine Storm. JCM 9, 2095. doi:10.3390/jcm9072095

Wang, B., Ilnytskyy, Y., Kovalchuk, I., and Kovalchuk, O. (2020). In Search of Preventative Strategies: novel High-CBD Cannabis sativa Extracts Modulate ACE2 Expression in COVID-19 Gateway Tissues. Aging 12, 22425-22444. doi:10.18632/aging.202225

Wang, D., Liu, X., Zhang, J., Wang, B., Xiang, H., Cheng, Z., et al. (2020). Clinical Characteristics of 138 Hospitalized Patients With 2019 Novel CoronavirusInfected Pneumonia in Wuhan, China. JAMA 323, 1061. doi:10.1001/jama. 2020.1585

Wen, C.-C., Kuo, Y.-H., Wang, S.-Y., Liu, H.-G., Lee, C.-K., Chang, S.-T., et al. (2007). Specific Plant Terpenoids and Lignoids Possess Potent Antiviral Activities Against Severe Acute Respiratory Syndrome Coronavirus. J. Med. Chem. 50, 4087-4095. doi:10.1021/jm070295s

Wu, Q. F., Shen, Z.-H., Ying, H.-Z., and Yu, C.-H. (2012). Chemical Compositions and Anti-Influenza Activities of Essential Oils From Mosla dianthera. J. Ethnopharmacol. 139, 668-671. doi:10.1016/j.jep.2011.11.056

Wu, C., Lee, H.-S., Hwang, K.-Y., and Lee, S.-J. (2014). Trans-Caryophyllene is a Natural Agonistic Ligand for Peroxisome Proliferator-Activated Receptor- $\alpha$. Bioorg. Med. Chem. Lett. 24, 3168-3174. doi:10.1016/j.bmcl.2014.04.112
Wyganowska-Swiatkowska, M., Nohawica, M., Grocholewicz, K., and Nowak, G. (2020). Influence of Herbal Medicines on HMGB1 Release, SARS-CoV-2 Viral Attachment, Acute Respiratory Failure, and Sepsis. A Literature Review. IJMS 21, 4639. doi:10.3390/ijms 21134639

Xie, Q., Liu, Z., and Li, Z. (2015). Chemical Composition and Antioxidant Activity of Essential Oil of Six Pinus taxa Native to China. Molecules 20, 9380-9392. doi: $10.3390 /$ molecules 20059380

Xu, G., Huang, K., and Zhou, J. (2018). Hepatic AMP Kinase as a Potential Target for Treating Nonalcoholic Fatty Liver Disease: Evidence From Studies of Natural Products. CMC 25, 889-907. doi:10.2174/ 0929867324666170404142450

Yamaguchi, M., and Levy, R. M. (2016). The Combination of $\beta$-Caryophyllene, Baicalin and Catechin Synergistically Suppresses the Proliferation and Promotes the Death of RAW267.4 Macrophages In Vitro. Int. J. Mol. Med. 38, 1940-1946. doi:10.3892/ijmm.2016.2801

Yamaguchi, M., and Levy, R. (2019). The Combination of Catechin, Baicalin and $\beta$-Caryophyllene Potentially Suppresses the Production of Inflammatory Cytokines in Mouse Macrophages In Vitro. Exp. Ther. Med. 17, 4312-4318. doi:10.3892/etm.2019.7452

Yamaguchi, M., and Levy, R. M. (2020). Metaxalone Suppresses Production of Inflammatory Cytokines Associated with Painful Conditions in Mouse Macrophages RAW264.7 Cells In Vitro: Synergistic Effect with $\beta$-Caryophyllene. $\quad C M M \quad 20, \quad 643-652 . \quad$ doi:10.2174/ 1566524020666200217102508

Yang, C., Hu, D. H., and Feng, Y. (2015). Antibacterial Activity and Mode of Action of the Artemisia capillaris Essential Oil and Its Constituents Against Respiratory Tract Infection-Causing Pathogens. Mol. Med. Rep. 11, 2852-2860. doi:10.3892/mmr.2014.3103

Yang, M., Lv, Y., Tian, X., An, R., Zhang, Q., Li, M., et al. (2017). Neuroprotective Effect of $\beta$-Caryophyllene on Cerebral IschemiaReperfusion Injury via Regulation of Necroptotic Neuronal Death and Inflammation: In Vivo and In Vitro. Front. Neurosci. 11, 583. doi:10.3389/ fnins.2017.00583

Yang, X., Yu, Y., and Xu, J.(2020). Clinical Course and Outcomes of Critically Ill Patients with SARS-CoV-2 Pneumonia in Wuhan, China: A Single-Centered, Retrospective, Observational Study. Lancet Respir. Med. 8, 475-481. doi:10. 1016/S2213-2600(20)30079-5

Younis, N. S., and Mohamed, M. E. (2019). $\beta$-Caryophyllene as a Potential Protective Agent Against Myocardial Injury: The Role of Toll-Like Receptors. Molecules 24, 1929. doi:10.3390/molecules24101929

Youssef, D. A., El-Fayoumi, H. M., and Mahmoud, M. F. (2019). BetaCaryophyllene Alleviates Diet-Induced neurobehavioral Changes in Rats: The Role of CB2 and PPAR- $\gamma$ Receptors. Biomed. Pharmacother. 110, 145-154. doi:10.1016/j.biopha.2018.11.039

Youssef, D. A., El-Fayoumi, H. M., and Mahmoud, M. F. (2019). Betacaryophyllene Protects against Diet-Induced Dyslipidemia and Vascular Inflammation in Rats: Involvement of $\mathrm{CB} 2$ and PPAR- $\gamma$ Receptors. Chem. Biol. Interact. 297, 16-24. doi:10.1016/j.cbi.2018.10.010

Zhang, Q., An, R., Tian, X., Li, M., Lou, J., Xu, L., et al. (2017). $\beta$-Caryophyllene Pretreatment Alleviates Focal Cerebral Ischemia-Reperfusion Injury by Activating PI3K/Akt Signaling Pathway. Neurochem. Res. 42, 1459-1469. doi:10.1007/s11064-017-2202-3

Zhang, Z., Yang, C., Dai, X., Ao, Y., and Li, Y. (2017). Inhibitory Effect of Trans-Caryophyllene (TC) on Leukocyte-Endothelial Attachment. Toxicol. Appl. Pharmacol. 329, 326-333. doi:10.1016/j. taap.2017.06.016

Zhang, C., Shi, L., and Wang, F. S. (2020). Liver Injury in COVID-19: Management and Challenges. Lancet Gastroenterol. Hepatol. 5, 428-430. doi:10.1016/S24681253(20)30057-1

Zhang, Y., Bai, C., Shi, W., Alvarez-Manzo, H., and Zhang, Y. (2020). Identification of Essential Oils Including Garlic Oil and Black Pepper Oil With High Activity against Babesia duncani. Pathogens 9, 466. doi:10.3390/ pathogens 9060466

Zheng, X., Sun, T., and Wang, X. (2013). Activation of Type 2 Cannabinoid Receptors (CB2R) Promotes Fatty Acid Oxidation through the SIRT1/PGC-1a Pathway. Biochem. Biophys. Res. Commun. 436, 377-381. doi:10.1016/j.bbrc. 2013.05.108 
Zhou, G., Chen, S., and Chen, Z. (2020). Advances in COVID-19: The Virus, The Pathogenesis, and Evidence-Based Control and Therapeutic Strategies. Front. Med. 14, 117-125. doi:10.1007/s11684020-0773-x

Zhou, H., Ma, J., Mao, C., Wang, J., and Gui, H. (2020). Cannabinoid Receptor 2 Promotes the Intracellular Degradation of HMGB1 via the AutophagyLysosome Pathway in Macrophage. Int. Immunopharmacol. 78, 106007. doi:10.1016/j.intimp.2019.106007

Zhu, Z., Shi, L., and Wang, Y. (2020). Pathological Findings of COVID-19 Associated With Acute Respiratory Distress Syndrome. Lancet Respir. Med. 8, 420-422. doi:10.1016/S2213-2600(20)30076-X
Conflict of Interest: The authors declare that the research was conducted in the absence of any commercial or financial relationships that could be construed as a potential conflict of interest.

Copyright (c) 2021 Jha, Sharma, Hashiesh, Arunachalam, Meeran, Javed, Patil, Goyal and Ojha. This is an open-access article distributed under the terms of the Creative Commons Attribution License (CC BY). The use, distribution or reproduction in other forums is permitted, provided the original author(s) and the copyright owner(s) are credited and that the original publication in this journal is cited, in accordance with accepted academic practice. No use, distribution or reproduction is permitted which does not comply with these terms. 